\title{
Manipulating local environment of atomically dispersed Fe electrocatalyst for high energy and long cycle Li-S pouch cell
}

Won-Gwang Lim

Korea Advanced Institute of Science and Technology

Cheol-Young Park

Korea Advanced Institute of Science and Technology

Hyeonjung Jung

Pohang University of Science and Technology

Seoa Kim

Korea Advanced Institute of Science and Technology

Seok Hun Kang

Electronics and Telecommunications Research Institute https://orcid.org/0000-0001-6725-7140

\section{Young-Gi Lee}

Electronics and Telecommunications Research Institute

\section{Yo Chan Jeong}

LG Energy Solution, Ltd.

\section{Seung Bo Yang}

LG Energy Solution, Ltd.

Kwonnam Sohn

LG Energy Solution, Ltd.

Jeong Woo Han

Pohang University of Science and Technology https://orcid.org/0000-0001-5676-5844

Jinwoo Lee ( $\sim$ jwlee1@kaist.ac.kr)

Korea Advanced Institute of Science and Technology https://orcid.org/0000-0001-6347-0446

\section{Article}

Keywords:

Posted Date: December 16th, 2021

DOI: https://doi.org/10.21203/rs.3.rs-1168100/v1 
License: (c) (i) This work is licensed under a Creative Commons Attribution 4.0 International License. Read Full License 


\section{Abstract}

High-energy lithium-sulfur (Li-S) pouch cell are limited by the insufficient capacities and stabilities of their cathodes under practical electrolyte/sulfur (E/S), electrolyte/capacity (E/C), and negative/positive (N/P) ratios. Herein, we fabricated an advanced cathode comprising highly active Fe single atom catalysts (SACs) and porous carbon to attain $361.8 \mathrm{~W} \mathrm{~h} \mathrm{~kg}^{-1} \mathrm{Li}$-S pouch cells satisfying low $\mathrm{E} / \mathrm{S}$ (2.0), E/C (1.9), and N/P (2.3) ratios with high sulfur loadings $\left(8.4 \mathrm{mg} \mathrm{cm}^{-2}\right)$. We designed high-activity Fe SACs by manipulating their local environments using electron exchangeable binding (EEB) sites. Introducing EEB sites composed of two different types of $S$ species, namely, thiophene-like-S and oxidized-S, adjacent to Fe SACs, promoted the kinetics of the $\mathrm{Li}_{2} \mathrm{~S}$ redox reaction by providing additional binding sites and modulating the Fe $d$-orbital levels via electron exchange with Fe. This desirable cathode electrocatalysis is maximized by the intimate contact of Fe SACs with the S species, confined together into porous carbon.

\section{Introduction}

Lithium-sulfur (Li-S) batteries are attracting world-wide attention owing to their high theoretical gravimetric energy density $\left(W_{\mathrm{G}}\right)$ values, which are required to attain $400-600 \mathrm{~W} \mathrm{~h} \mathrm{~kg}^{-1}$ pouch cells to practically compete with commercial lithium ion batteries (LIBs, 250-300 $\mathrm{W} \mathrm{h} \mathrm{kg}^{-1}$ ). ${ }^{1,2}$ However, the lithium polysulfide (LiPS) shuttling phenomenon and sluggish reaction kinetics in the cathode limit the $W_{G}$ of a Li-S battery. ${ }^{3-6}$ Although the pioneering Li-S battery corporations (Sion Power and Oxis Energy) developed 400-450 W h kg-1 prototype with advanced pouch cell manufacturing technology, most Li-S pouch cells in academic research still exhibit similar levels of $W_{G}$ compared to LIBs, despite significant improvements on the coin-cell level. ${ }^{7-10}$ It is because high-performance coin-cell was achieved under flooded electrolyte, excess $\mathrm{Li}(>500 \%)$, and low S loading $\left(<4 \mathrm{mg} \mathrm{cm}^{-2}\right)$ conditions, which were favorable for a high capacity and cycle stability but led to "fat" Li-S cells. ${ }^{11-14}$ To develop "light" Li-S pouch cells with high energies, a rational cathode design is needed with sufficiently low electrolyte/sulfur $\left(E / S<5 \mu \mathrm{L} \mathrm{mg}^{-1}\right)$, electrolyte/capacity $\left(\mathrm{E} / \mathrm{C}<5 \mu \mathrm{L}[\mathrm{mA} \mathrm{h}]^{-1}\right)$, and negative/positive capacity $(\mathrm{N} / \mathrm{P}<5)$ ratios, and a high $\mathrm{S}$ loading $\left(>5 \mathrm{mg} \mathrm{cm}^{-2}\right)$, to minimize the amount of excess $\mathrm{Li}$ and electrolyte. ${ }^{12,15-17}$

Electrocatalysis is at the forefront of Li-S cathode design technology because the multi-functional electrocatalysts based on the adsorption/conversion behaviors of $S$ species allow the cathode to exhibit a high capacity and stable cycle even under a high S loading, with low E/S and N/P ratios (Supplementary Fig. 1). ${ }^{18-22}$ In particular, single atom catalysts (SACs) are the most promising owing to their following exceptional characteristics (Supplementary Fig. 2a): i) SACs exhibit high atom utilization efficiencies, so minimizing catalyst contents in the electrode, and offers the opportunity to deliver highenergy pouch cells, ${ }^{23,24}$ ii) SACs allow the direct conversion of adsorbed LiPS to the final products without an additional sluggish diffusion step. The superior qualities of SACs motivate efforts toward developing SAC-embedded cathodes for high-energy Li-S cells. ${ }^{25-27}$ However, they are disrupted by the 
intrinsic limitations of SACs, including unsatisfactory catalytic activities and weak adsorption strength with $\mathrm{S}$ species (due to the Lewis acid-base interaction with single-end binding). ${ }^{28,29}$ Consequently, metal compound ( $\mathrm{M}_{\mathrm{a}} \mathrm{X}_{\mathrm{b}}, \mathrm{M}=$ metal and $\mathrm{X}=$ anion) based particle-type catalysts (PTCs) are used together with SACs in the cathode, owing to their strong adsorption abilities with LiPS by forming M-S and X-Li bonds. ${ }^{25,30}$ However, PTCs decrease the atom utilization efficiency, which necessitates a high catalyst content (10-30 wt\%) in the cathode, ${ }^{31,32}$ restricting the $W_{\mathrm{G}}$ values of the Li-S pouch cells (Supplementary Fig. 2b). Moreover, an additional LiPS diffusion step is inevitable because of the low electrical conductivities of most PTCs. ${ }^{33}$ Consequently, state-of-the-art SAC-based cathodes exhibit unsatisfactory pouch cell performances ( $<300 \mathrm{~W} \mathrm{~h} \mathrm{~kg}^{-1}$, considering all pouch cell components) and cycle life $(<70$ cycles) (Supplementary Fig. 3). In this regard, strategies to enhance the sulfur adsorption properties and catalytic activities of SACs are required for the fabrication of Li-S pouch cells with a higher $W_{\mathrm{G}}$ than the currently known cells.

Herein, we propose a concept for designing highly active Fe-N-C catalysts by manipulating their local environment using electron exchangeable binding (EEB) sites for achieving high-energy Li-S pouch cells (Fig. 1a). EEB sites adjacent to the Fe-N-C catalysts provide additional binding sites for the $\mathrm{S}$ species and modulate the Fe $d$-orbital energy level via electron exchange with the Fe atom. These multi-functional EEB sites enhance the LiPS adsorption properties and $\mathrm{Li}_{2} \mathrm{~S}$ redox kinetics, leading to highly active Fe SACs that are distinctly different from conventional SACs. Especially, the mesoporous carbon host holds the Fe SACs, electrolytes, and S species together, stably retaining the triple-phase boundaries for $\mathrm{Li}^{+}$ioncatalysts-electron (Fig. 1b). This specially designed cathode with desirable Li-S electrochemistry enables high energy (325.4 $\mathrm{W} \mathrm{h} \mathrm{kg}^{-1}$ ) Li-S pouch cells with stable cycle life up to 80 cycles. We also successfully fabricated a $361.8 \mathrm{~W} \mathrm{~h} \mathrm{~kg}^{-1} \mathrm{Li}-\mathrm{S}$ pouch cell satisfying low E/S $\left(2.0 \mu \mathrm{L} \mathrm{mg}^{-1}\right), \mathrm{E} / \mathrm{C}\left(1.9 \mu \mathrm{L}[\mathrm{mA} \mathrm{h}]^{-1}\right)$, and $\mathrm{N} / \mathrm{P}(2.3)$ ratios with a high $\mathrm{S}$ loadings of $8.4 \mathrm{mg} \mathrm{cm}^{-2}$.

\section{Main Text}

\section{Manipulation of the local environment of Fe SACs with EEB sites}

Based on the biological phenomenon where the redox catalysis of cytochrome is altered by the oxygen binding properties of different functional groups around the Fe-N-C sites (Supplementary Fig. 4), we designed highly active $\mathrm{Fe}-\mathrm{N}-\mathrm{C}$ catalysts in mesoporous carbon by manipulating their local environments using EEB sites comprising two different $S$ species: thiophene-like-S (-S) and oxidized-S (- $\left.\mathrm{SO}_{2}\right)$ (Fig. 2a). Two different precursors: dibenzyl disulfide (DBDS) and sodium metabisulfite $\left(\mathrm{Na}_{2} \mathrm{~S}_{2} \mathrm{O}_{5}\right)$ were used to modulate the atomic ratios of the $-\mathrm{S}$ and $-\mathrm{SO}_{2}$ species for the design of highly optimized EEB sites. Scanning electron microscopy (SEM) and transmission electron microscopy (TEM) images of the asprepared mesoporous carbon clearly show well-developed porous architectures (Supplementary Fig. 5a and b), consistent with the nitrogen physisorption results (Supplementary Fig. 6). Even after introducing Fe-N-C, the three different SACs, namely, Fe-N-C without EEB sites (FeNC), Fe-N-C with DBDS-derived EEB 
sites (FeNC-EEB-1), and Fe-N-C with $\mathrm{Na}_{2} \mathrm{~S}_{2} \mathrm{O}_{5}$-derived EEB sites (FeNC-EEB-2), still showed mesopores (Supplementary Fig. 7), and the materials exhibited similar surface areas, pore sizes, and pore volumes (Supplementary Fig. 8 and Supplementary Table 1).

The local Fe-N-C environment was investigated using X-ray spectroscopy and electron microscopy techniques. First, X-ray photoelectron spectroscopy (XPS) S 2p spectra of FeNC-EEB-1 and FeNC-EEB-2 exhibit two characteristic peaks of $-S$ at 163.7 and $164.9 \mathrm{eV}$ corresponding to $C-S-C 2 p 3 / 2$ and C-S-C $2 p$ $1 / 2$, respectively and one characteristic peak of $-\mathrm{SO}_{2}$ at $168.0 \mathrm{eV}$ (Fig. $2 \mathrm{~b}$ and C), indicating that the EEB sites derived from DBDS and $\mathrm{Na}_{2} \mathrm{~S}_{2} \mathrm{O}_{5}$ are composed of $-\mathrm{S}$ and $-\mathrm{SO}_{2}$ species. ${ }^{34}$ However, the $-\mathrm{SO}_{2} /-\mathrm{S}$ ratio of the EEB sites adjacent to Fe-N-C was highly dependent on different precursors (Fig. 2d). The FeNC-EEB1 (0.12) exhibits a $\sim 5$ times lower $-\mathrm{SO}_{2} /$-S ratio than FeNC-EEB-2 (0.63). This is because $\mathrm{Na}_{2} \mathrm{~S}_{2} \mathrm{O}_{5}$ is a more suitable precursor to form - $\mathrm{SO}_{2}$ species at high temperatures owing to its higher atomic $\mathrm{O}$ fraction compared to DBDS. ${ }^{35}$ Furthermore, Fe and $\mathrm{N}$ atomic contents are similar in all the materials (Fig. $2 \mathrm{~d}$, Supplementary Fig. 9 and 10). Second, the high-angle annular dark-field scanning transmission electron microscopy (STEM) image of FeNC shows atomically dispersed Fe in the carbon matrix (Supplementary Fig. 11a). These Fe single atoms were also observed in FeNC-EEB-1 and FeNC-EEB-2 (Fig. 2e and Supplementary Fig. 11b), indicating the existence of Fe SACs inside the porous carbon. Moreover, the energy dispersive spectroscopic (EDS) mapping images of FeNC-EEB-1 and FeNC-EEB-2 represent the homogeneous distributions of $\mathrm{Fe}, \mathrm{N}, \mathrm{C}, \mathrm{S}$, and $\mathrm{O}$ along the particles, implying the formation of $\mathrm{Fe}-\mathrm{N}-\mathrm{C}$ and EEB sites (Supplementary Fig. 12).

To study the chemical states of Fe-N-C, Fe K-edge X-ray absorption spectroscopy (XAS) was performed. ${ }^{36}$ In the Fourier-transformed extended X-ray absorption fine structure (FT-EXAFS) spectrum of the Fe foil, the Fe-Fe metallic bonding peak is observed at $2.2 \AA$ (Fig. 2f). ${ }^{37}$ However, this Fe-Fe peak disappeared and new peaks corresponding to Fe-N and Fe-C appeared at 1.4 and $2.4 \AA_{1}^{37}$ respectively in the spectra of FeNC, FeNC-EEB-1, and FeNC-EEB-2, demonstrating the presence of Fe-N-C sites without Fe metallic particles. The X-ray diffraction (XRD) results also indicated the absence of other crystalline phases (e.g., Fe metal and iron nitride) (Supplementary Fig. 13). Furthermore, the X-ray absorption near-edge structure (XANES) spectra showed that the white line intensity of FeNC-EEB-2 was higher than that of FeNC, whereas FeNC-EEB-1 exhibited a lower white line intensity than FeNC (Fig. 2g). FeNC-EEB-1 has a low $\mathrm{SO}_{2} /$-S ratio and exhibits an upshift of the $\mathrm{Fe} d$-band center, implying that electrons transfer from the neighboring EEB sites to Fe. In contrast, FeNC-EEB-2 has a high $-\mathrm{SO}_{2} /-\mathrm{S}$ ratio and shows a downshift of the Fe $d$-band center, indicating that electrons transfer from Fe to the EEB sites. ${ }^{34}$ To verify the electron exchange between $\mathrm{Fe}$ and $-\mathrm{SO}_{2} /-\mathrm{S}$ EEB sites, density functional theory (DFT) calculations were performed (Supplementary Fig. 14). ${ }^{34}$ The -S species represent the electron donation to Fe- $\mathrm{N}-\mathrm{C}$, corresponding to an increase in the $\mathrm{Fe} d$-orbital level, while the $-\mathrm{SO}_{2}$ species show the electron withdrawal from $\mathrm{Fe}-\mathrm{N}-\mathrm{C}$, indicating a decrease in the Fe $d$-orbital level. This is consistent with the tendency of observed in the XANES spectra, demonstrating that the introduction of EEB sites with different $-\mathrm{SO}_{2} /-\mathrm{S}$ ratios near the Fe$\mathrm{N}-\mathrm{C}$ catalysts leads to the modulation of $d$-orbitals of Fe SACs by electron exchange. 


\section{$\mathrm{Li}_{2} \mathrm{~S}$ redox kinetics on Fe SACs}

Effects of the local Fe-N-C environment, manipulated by EEB sites, on the Li-S electrochemistry were studied using a coin-cell. The cyclic voltammetry curve of FeNC-EEB-1 exhibits two cathodic peaks I and II at higher potentials than FeNC (Supplementary Fig. 15), indicating that the EEB sites with a low $-\mathrm{SO}_{2} /-\mathrm{S}$ ratio near Fe-N-C decrease the reduction overpotential. However, FeNC-EEB-2 exhibits similar potentials of cathodic peaks I and II as those of FeNC, implying that the EEB sites with high $-\mathrm{SO}_{2} /-\mathrm{S}$ ratios are not much effective in decreasing the reduction overpotential. In the oxidation reaction, both FeNC-EEB-1 and FeNC-EEB-2 exhibit the anodic peak III at a lower potential than FeNC, indicating that both EEB sites improve the oxidation overpotential. Tafel plots were obtained to further evaluate the sulfur redox kinetics (Fig. 3a). The Tafel slope of FeNC-EEB-1 was much lower than that of FeNC, while the Tafel slope of FeNC-EEB-2 was slightly lower than that of FeNC for the cathodic reaction. In the anodic reaction, both FeNC-EEB-1 and FeNC-EEB-2 exhibited lower Tafel slopes than FeNC, demonstrating that the - $\mathrm{SO}_{2} /$-S EEB sites near the $\mathrm{Fe}-\mathrm{N}-\mathrm{C}$ catalysts improved the sulfur redox kinetics.

Potentiostatic analyses were performed to understand the enhanced kinetics of sulfur electrochemistry by EEB sites on the $\mathrm{Li}_{2} \mathrm{~S}$ nucleation/dissociation behaviors. During the potentiostatic discharge at $2.05 \mathrm{~V}$, FeNC-EEB-1 exhibited the maximum current time $\left(t_{m}\right)$ at $227 \mathrm{~s}$, which was earlier than that of FeNC (Fig. $3 \mathrm{~b}$ and Supplementary Fig. 16a). The FeNC-EEB-2 exhibited the $t_{m}$ at $320 \mathrm{~s}$, which was slightly earlier than FeNC but later than FeNC-EEB-1 (Supplementary Fig. 16b). Considering that the $t_{m}$ is highly related to the $\mathrm{Li}_{2} \mathrm{~S}$ nucleation density $\left(N_{o}\right)$ and growth rate $\left(k^{2}\right)$ as follows, ${ }^{38}$

$t_{\mathrm{m}}=\left(2 \pi N_{\mathrm{o}} k^{2}\right)^{-0.5}$

the lowest $t_{m}$ in FeNC-EEB- 1 indicates that $\mathrm{Li}_{2} \mathrm{~S}$ nucleation is promoted by EEB sites with a low $-\mathrm{SO}_{2} /-\mathrm{S}$ ratio. The enhanced $\mathrm{Li}_{2} \mathrm{~S}$ nucleation in FeNC-EEB-1 leads to a higher $\mathrm{Li}_{2} \mathrm{~S}$ nucleation capacity $(213.3 \mathrm{~mA}$ $\mathrm{h} \mathrm{g}^{-1}$ ) than FeNC (185.3 mA h g ${ }^{-1}$ ) (Supplementary Fig. 16c). The $\mathrm{Li}_{2} \mathrm{~S}$ nucleation capacity of FeNC-EEB-2 $\left(196.8 \mathrm{~mA} \mathrm{~h} \mathrm{~g}^{-1}\right)$ is slightly higher than that of FeNC but lower than that of FeNC-EEB-1. During the potentiostatic charge at $2.35 \mathrm{~V}$, the FeNC-EEB-1 exhibited a lower $t_{m}(360 \mathrm{~s})$ and higher $\mathrm{Li}_{2} \mathrm{~S}$ dissociation capacity (457.2 $\mathrm{mA} \mathrm{h} \mathrm{g}^{-1}$ ) than FeNC (Fig. 3c and Supplementary Fig. 16d). The FeNC-EEB-2 also exhibited a lower $t_{m}(489 \mathrm{~s})$ and higher $\mathrm{Li}_{2} \mathrm{~S}$ dissociation capacity $\left(381.5 \mathrm{~mA} \mathrm{~h} \mathrm{~g}^{-1}\right)$ than FeNC, but they were less effective than those of FeNC-EEB-1 (Supplementary Fig. 16e and f). In situ XRD analyses were further performed to directly characterize the $\mathrm{Li}_{2} \mathrm{~S}$ redox kinetics (Supplementary Fig. 17). During the first discharge/charge, FeNC-EEB-1 exhibited a highly reversible conversion reaction between $\mathrm{S}_{8}$ and $\mathrm{Li}_{2} \mathrm{~S}$ (Fig. $3 \mathrm{~d}$ and e). Especially, $\mathrm{Li}_{2} \mathrm{~S}$ nucleated and dissociated at the early stages of the $\mathrm{B}$ and $\mathrm{C}$ regions, respectively (Fig. 3f). Although FeNC-EEB-2 also exhibited reversible $\mathrm{S}_{8}$ and $\mathrm{Li}_{2} \mathrm{~S}$ redox reactions (Supplementary Fig. 18), $\mathrm{Li}_{2} \mathrm{~S}$ nucleated and dissociated at a later stage of $\mathrm{B}$ and $\mathrm{C}$ than FeNC-EEB-1 (Fig. 3f). The overall $\mathrm{Li}_{2} \mathrm{~S}$ peak intensity of FeNC was lower than those of FeNC-EEB-1 and FeNC-EEB-2 owing to the lower $\mathrm{Li}_{2} \mathrm{~S}$ redox activity (Supplementary Fig. 19 and Fig. 3f). The $\mathrm{Li}_{2} \mathrm{~S}$ kinetic analyses 
demonstrate that i) introducing $-\mathrm{SO}_{2} /-\mathrm{S}$ EEB sites adjacent to $\mathrm{Fe}-\mathrm{N}-\mathrm{C}$ improves the kinetics of the $\mathrm{Li}_{2} \mathrm{~S}$ associated conversion reaction on $\mathrm{Fe}-\mathrm{N}-\mathrm{C}$, and ii) EEB sites with low $-\mathrm{SO}_{2} /-\mathrm{S}$ ratios are more effective in promoting $\mathrm{Li}_{2} \mathrm{~S}$ nucleation/dissociation reactions on Fe-N-C catalysts than EEB sites with high $-\mathrm{SO}_{2} /-\mathrm{S}$ ratios.

To unveil the origin of the kinetic improvements of the $\mathrm{Li}_{2} \mathrm{~S}$ electrochemistry by EEB sites, DFT calculations were performed (Supplementary Fig. 20). Three model systems, namely, pristine Fe-N-C

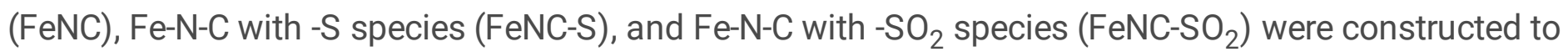
differentiate the effects of two different types of $-\mathrm{S}$ and $-\mathrm{SO}_{2}$ EEB sites on the electrocatalysis of Fe-N-C (Supplementary Fig. 20b). In all three models, Li atom of LiPS formed a bond with Fe atom in Fe-N-C. The calculated LiPS adsorption energy ( $\left.E_{a d}\right)$ of FeNC-S was slightly lower (stronger adsorption strength) than that of FeNC, (Fig. 4a). This is attributed to the $-\mathrm{S}$ species adjacent to Fe-N-C, increasing the Fe $d$-band center of Fe-N-C by their electron donating properties and thus resulting in the stronger adsorption to $\mathrm{Fe}$ of Li atom in LiPS (as demonstrated in Fig. $2 \mathrm{~g}$ and Supplementary Fig. 14). ${ }^{39,40}$ In addition, the -S species formed the moderate bond with Li atom of LiPS. However, although the downshifted Fe $d$-band center of Fe-N-C induced by electron withdrawing properties of neighboring $-\mathrm{SO}_{2}$ species (as shown in Fig. $2 \mathrm{~g}$ and Supplementary Fig. 14) is expected to increase the $\mathrm{E}_{\mathrm{ad}},{ }^{41} \mathrm{FeNC} \mathrm{SO}_{2}$ exhibits a much lower $\mathrm{E}_{\mathrm{ad}}$ (stronger adsorption strength) than FeNC and FeNC-S (Fig. 4a). This is attributed to the $-\mathrm{SO}_{2}$ species adjacent to Fe-N-C providing additional binding sites and forming quite strong bonds between $\mathrm{O}$ atoms of $-\mathrm{SO}_{2}$ and $\mathrm{Li}$ atoms of LiPS (Fig. 4b and Supplementary Fig. 21c), which implies that the - $\mathrm{SO}_{2}$ and $-\mathrm{S}$ species that surround Fe-N-C exhibit completely different LiPS adsorption behaviors. Moreover, the change in the reaction energy $(\Delta E)$ was evaluated for each reaction pathway (Fig. 4c). First, $\Delta E$ value for the reduction of $\mathrm{S}_{8}$ to $\mathrm{Li}_{2} \mathrm{~S}_{8}$ indicates an exothermic reaction, and the subsequent four steps for the further reduction of $\mathrm{Li}_{2} \mathrm{~S}_{8}$ to $\mathrm{Li}_{2} \mathrm{~S}$ through several intermediates (i.e., $\mathrm{Li}_{2} \mathrm{~S}_{6}, \mathrm{Li}_{2} \mathrm{~S}_{4}$, and $\mathrm{Li}_{2} \mathrm{~S}_{2}$ ) exhibit the coexistence of exothermic and endothermic reactions. Among these steps, the reduction reaction from $\mathrm{Li}_{2} \mathrm{~S}_{4}$ to $\mathrm{Li}_{2} \mathrm{~S}$ exhibits the strong endothermic reaction in all the catalyst model systems, indicating that the kinetics of the sulfur reduction reaction is highly dependent on the energy barrier to nucleate the $\mathrm{Li}_{2} \mathrm{~S}$ from $\mathrm{Li}_{2} \mathrm{~S}_{4}$. For FeNC, $\triangle E$ for the reduction of $\mathrm{Li}_{2} \mathrm{~S}_{4}$ to $\mathrm{Li}_{2} \mathrm{~S}$ is $1.41 \mathrm{eV}$ (Fig. 4c and d). However, FeNC-S exhibits a lower $\Delta E(1.24 \mathrm{eV})$ than $\mathrm{FeNC}$, whereas FeNC-SO ${ }_{2}$ exhibits a higher $\Delta E(1.62 \mathrm{eV})$ than FeNC for the reduction of $\mathrm{Li}_{2} \mathrm{~S}_{4}$ to $\mathrm{Li}_{2} \mathrm{~S}$. These DFT calculations verify that both the $-\mathrm{S}$ and $-\mathrm{SO}_{2}$ species near Fe-N-C increase the adsorption strength of LiPS by providing additional binding sites and by modulating the Fe $d$-orbital level with electron exchange. Nevertheless, the -S species which increase the LiPS adsorption strength to a moderate level, improve the Li-S electrochemistry kinetics on Fe SACs, whereas the $-\mathrm{SO}_{2}$ species which increase the LiPS adsorption strength to a high level, deteriorate the Li-S electrochemistry kinetics on Fe-N-C (Fig. 4e). These DFT results support that the FeNC-EEB-1, with 5 times lower $-\mathrm{SO}_{2} /-\mathrm{S}$ ratio than FeNC-EEB-2, more effectively enhances the $\mathrm{Li}_{2} \mathrm{~S}$ electrocatalysis than FeNC-EEB-2.

\section{Li-S performance in coin-cell configuration}


Before fabricating the pouch cell, the coin-cell performance was investigated. Compared to mesoporous carbon (Supplementary Fig. 22a), FeNC exhibited a higher initial discharge capacity (1125 mA h g $\mathrm{g}^{-1}$ ) at a $0.2 \mathrm{C}$ rate, owing to the electrocatalysis of Fe-N-C (Fig. 5a). FeNC-EEB-1 and FeNC-EEB-2 showed discharge capacities of 1324 and $1179 \mathrm{~mA} \mathrm{~h} \mathrm{~g}^{-1}$, respectively, higher than those of FeNC. The polarization degree was also improved in FeNC-EEB-1 (0.17 V) and FeNC-EEB-2 (0.185 V), compared to that of FeNC (0.205 V) (Fig. 5b). Meanwhile, FeNC-EEB-1 exhibited a higher initial discharge capacity and lower polarization than FeNC-EEB-2, which was consistent with the results of the $\mathrm{Li}_{2} \mathrm{~S}$ kinetic studies. The cycle stability results show that mesoporous carbon exhibited only $627 \mathrm{~mA} \mathrm{~h} \mathrm{~g}^{-1}$ after 100 cycles (Supplementary Fig. 22b), whereas FeNC exhibited $864 \mathrm{~mA} \mathrm{~h} \mathrm{~g}^{-1}$ after 200 cycles (Supplementary Fig. 23). In FeNC-EEB-1, a discharge capacity of $1030 \mathrm{~mA} \mathrm{~h} \mathrm{~g}^{-1}$ ( 20\% higher than FeNC) was retained after 200 cycles. FeNC-EEB-2 showed $925 \mathrm{~mA} \mathrm{~h} \mathrm{~g}^{-1}$ after 200 cycles, which was $~ 7 \%$ higher than that of FeNC, but $\sim 10 \%$ lower than that of FeNC-EEB-1. Rate capabilities were also investigated at different current densities from 0.3 to $2.0 \mathrm{C}$ rate (Fig. $5 \mathrm{c}$ ). The FeNC-EEB-2 exhibited a slightly improved rate capability compared to FeNC, although FeNC-EEB-1 showed a highly improved capacity retention (78.4\%) at a $2.0 \mathrm{C}$ rate compared to FeNC (70.0\%) and FeNC-EEB-2 (73.3\%) (Supplementary Fig. 24). Additionally, FeNC-EEB1 exhibited the lowest polarization at all currents (Supplementary Fig. 25a). In FeNC-EEB-2, the polarization was higher than FeNC-EEB-1, but lower than FeNC. Moreover, plateau discharge capacity $\left(\mathrm{Q}_{D}\right)$ fractions of FeNC-EEB-1 were higher than FeNC-EEB-2 and FeNC electrodes throughout all currents (Supplementary Fig. 25b), indicating that $\mathrm{Li}_{2} \mathrm{~S}_{4}$ is most easily converted to $\mathrm{Li}_{2} \mathrm{~S}$ in FeNC-EEB-1. To further characterize the cathode state after cycling, time of secondary ion mass spectrometry (ToF-SIMS) analysis was performed. The $\mathrm{S}^{-}$surface profile images of FeNC-EEB-1 and FeNC-EEB-2 represents weak intensities of secondary $S^{-}$ions (Fig. 5 d), whereas FeNC exhibits a high-intensity $S^{-}$region owing to the many $S$ agglomerates. Meanwhile, the ToF-SIMS depth profiles showed that the $\mathrm{S}^{-}$intensities of cycled FeNC-EEB-1 and FeNC-EEB-2 increased as the sputtering time increased, while the $\mathrm{S}^{-}$intensity decreased in FeNC (Fig. 5e), which agreed with ToF-SIMS 3D rendered images (Fig. $5 f$ and Supplementary Fig. 26). This indicates that the $S$ species are severely diffused and deposited on the external part of the electrode during cycling in FeNC owing to poor electrocatalysis (Supplementary Fig. 27). Conversely, the S species are well-preserved within the internal part of the electrode in FeNC-EEB-1 and FeNC-EEB-2 because the improved electrocatalysis inhibits the shuttle effect (Fig. $5 \mathrm{~g}$ ). These coin-cell studies suggest that introducing $-\mathrm{SO}_{2}$ /-S EEB sites adjacent to the $\mathrm{Fe}-\mathrm{N}$-C catalysts promotes sulfur redox kinetics, achieving Li-S cells with high capacities, cycle stabilities, rate capabilities, and low polarizations (Supplementary Fig. 28). Especially, EEB sites with low $-\mathrm{SO}_{2} /-\mathrm{S}$ ratios are more suitable for efficiently enhancing the catalytic activity of Fe-N-C than those with high $-\mathrm{SO}_{2} /-\mathrm{S}$ ratios. This is because the $-\mathrm{S}$ species near Fe-N-C moderately modulates the LiPS binding energy and lowers the energy barrier for the conversion reaction between $\mathrm{Li}_{2} \mathrm{~S}_{4}$ and $\mathrm{Li}_{2} \mathrm{~S}$ compared to the $-\mathrm{SO}_{2}$ species, which increases the LiPS binding energy too high.

Consequently, FeNC-EEB-1 exhibited ultrahigh cycle stabilities even at high current densities. At a $1.0 \mathrm{C}$ rate, an initial discharge capacity of $1011 \mathrm{~mA} \mathrm{~h} \mathrm{~g}^{-1}$ was exhibited, and $~ 80 \%$ of the initial capacity (808 $\mathrm{mA} \mathrm{h} \mathrm{^{-1 }}$ ) was retained even after 250 cycles, with a capacity decay ratio per cycle of only $0.08 \%$ 
(Supplementary Fig. 29). Furthermore, FeNC-EEB-1 exhibited initial discharge capacities of 895 and 728 $\mathrm{mA} \mathrm{h} \mathrm{g} \mathrm{g}^{-1}$ at a 2.0 and $3.0 \mathrm{C}$ rate, respectively. After $250 \mathrm{cycles}, 735 \mathrm{~mA} \mathrm{~h} \mathrm{~g}^{-1}$ was maintained at a $2.0 \mathrm{C}$ rate with a retention ratio of $82.1 \%$ and capacity decay ratio per cycle of $0.07 \%$, whereas $495 \mathrm{~mA} \mathrm{~h} \mathrm{~g}^{-1}$ was maintained even at a $3.0 \mathrm{C}$ rate. To determine whether FeNC-EEB-1 can meet satisfactory levels of areal sulfur loading and E/S ratio and E/C ratios, a Li-S coin cell was operated under harsh conditions with an areal sulfur loading of $5.0 \mathrm{mg} \mathrm{cm}^{-2}$ and an $\mathrm{E} / \mathrm{S}$ ratio of $4.0 \mu \mathrm{L} \mathrm{mg}^{-1}$ (Fig. $5 \mathrm{~h}$ ). At a $0.1 \mathrm{C}$ rate, the areal discharge capacity of $4.76 \mathrm{~mA} \mathrm{~h} \mathrm{~cm}^{-2}\left(952 \mathrm{~mA} \mathrm{~h} \mathrm{~g}^{-1}\right)$ was exhibited with an E/C ratio of $4.2 \mu \mathrm{L}$ [mA $\mathrm{h}^{-1}$. Even after 100 cycles, the areal capacity of $4.06 \mathrm{~mA} \mathrm{~h} \mathrm{~cm}^{-2}\left(812 \mathrm{~mA} \mathrm{~h} \mathrm{~g}^{-1}\right)$ was exhibited with an E/C

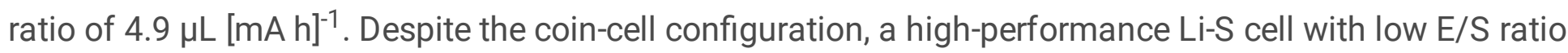
$\left(4 \mu \mathrm{L} \mathrm{mg}^{-1}\right)$ and $\mathrm{E} / \mathrm{C}\left(4.2 \mu \mathrm{L}[\mathrm{mA} \mathrm{h}]^{-1}\right)$ ratios and a high areal sulfur loading $\left(5.0 \mathrm{mg} \mathrm{cm}^{-2}\right)$ were achieved by introducing $-\mathrm{SO}_{2} /$-S EEB sites to promote the electrocatalysis of Fe SACs (Supplementary Fig. 30 and Supplementary Table 2).

\section{Fabrication of Li-S pouch cell}

First, a $2.5 \mathrm{~cm}$ ' $2.5 \mathrm{~cm}$ pouch cell was fabricated using a FeNC-EEB-1 cathode with a $3.6 \mathrm{mg} \mathrm{cm}^{-2} \mathrm{~S}$ loading and $100 \mu \mathrm{m} \mathrm{Li} \mathrm{metal} \mathrm{anode} \mathrm{(Supplementary} \mathrm{Fig.} \mathrm{31).} \mathrm{To} \mathrm{satisfy} \mathrm{the} \mathrm{E/S} \mathrm{ratio} \mathrm{of} 4.0 \mu \mathrm{L} \mathrm{mg}{ }^{-1}$, the electrolyte content in the pouch cell was controlled to $58 \mathrm{wt} \%$ (Supplementary Fig. 32 and Supplementary Table 3). The as-fabricated pouch cell exhibited an initial discharge capacity of 1340 and $1117 \mathrm{~mA} \mathrm{~h} \mathrm{~g}^{-1}$ at 0.18 and $0.36 \mathrm{~mA} \mathrm{~cm}^{-2}$, respectively (Supplementary Fig. 33). Although this pouch cell exhibited a stable cycle life ( $90 \%$ capacity retention) up to 20 cycles with an E/S ratio of $4.0 \mu \mathrm{L} \mathrm{mg}^{-1}$ at $0.18 \mathrm{~mA} \mathrm{~cm}^{-}$ 2 (Fig. 6a), the $W_{\mathrm{G}}$ was limited to $160 \mathrm{~W} \mathrm{~h} \mathrm{~kg}^{-1}$, owing to unsatisfactory levels of $S$ loading in the cathode (only $5.6 \mathrm{wt} \%$ of the pouch cell as suggested in Supplementary Fig. 32), as well as N/P (4.3), and E/C $\left(7.6 \mu \mathrm{L}\left[\mathrm{mA} \mathrm{h}^{-1}\right)\right.$ ratios. Considering the relationship between the total $W_{\mathrm{G}}, \mathrm{E} / \mathrm{S}$ ratio, and $\mathrm{S}$ loading, the pouch cells require $S$ loadings $>8 \mathrm{mg} \mathrm{cm}^{-2}$ and $\mathrm{E} / \mathrm{S}$ ratios $<4.0 \mu \mathrm{L} \mathrm{mg}^{-1}$ to achieve a high $W_{\mathrm{G}}(>300 \mathrm{Wh}$ $\mathrm{kg}^{-1}$ ) (Fig. 6b). Therefore, we fabricated a $4 \mathrm{~cm}^{\prime} 4 \mathrm{~cm}$ FeNC-EEB-1 cathode with a total S loading of 134.7 $\mathrm{mg}\left(8.4 \mathrm{mg} \mathrm{cm}^{-2}\right)$ (Supplementary Fig. 34a). With an E/S ratio of $4.0 \mu \mathrm{L} \mathrm{mg}^{-1}$, the sulfur content in the pouch cell increased to $12.3 \mathrm{wt} \%$ and the electrolyte content decreased to $49.5 \mathrm{wt} \%$ (Supplementary Fig. 34b and Supplementary Table 4). The as-fabricated pouch cell showed an initial discharge capacity of $1258 \mathrm{~mA} \mathrm{~h} \mathrm{~g}^{-1}$ (areal capacity of $10.6 \mathrm{~mA} \mathrm{~h} \mathrm{~cm}^{-2}$ ) at $0.42 \mathrm{~mA} \mathrm{~cm}^{-2}$, achieving a high $W_{\mathrm{G}}$ of $325.4 \mathrm{~W} \mathrm{~h} \mathrm{~kg}^{-1}$ with E/C and N/P ratios of $3.2 \mu \mathrm{L}^{\mathrm{mA} \mathrm{h}}{ }^{-1}$ and 2.0 (only $100 \%$ excess $\mathrm{Li}$ ), respectively (Supplementary Fig. 35 and Fig. 6c). The cell exhibited a stable cycle life for 80 cycles, maintaining a high Coulombic efficiency (>95\%). After 80 cycles, the discharge capacity was $906 \mathrm{~mA} \mathrm{~h} \mathrm{~g}^{-1}$ with a $72 \%$ retention ratio of the initial capacity (Supplementary Fig. 36). In addition to the $325.4 \mathrm{~W} \mathrm{~h} \mathrm{~kg}^{-1}$ pouch cell, we attempted to fabricate a Li-S pouch cell with an $W_{\mathrm{G}}$ higher than $350 \mathrm{~W} \mathrm{~h} \mathrm{~kg}^{-1}$. The electrolyte amount added in the pouch cell was extremely decreased to satisfy an E/S ratio of $2.0 \mu \mathrm{L} \mathrm{mg}^{-1}$ (only $32.9 \mathrm{wt} \%$ of the pouch cell) (Supplementary Fig. 37 and Supplementary Table 5). The as-prepared $4 \mathrm{~cm}^{\prime} 4 \mathrm{~cm}$ Li-S pouch cell featuring the FeNC-EEB-1 cathode with a S loading of $8.4 \mathrm{mg} \mathrm{cm}^{-2}$ and an E/S ratio of $2.0 \mu \mathrm{L} \mathrm{mg}{ }^{-1}$ 
exhibited an $W_{\mathrm{G}}$ of $361.8 \mathrm{~W} \mathrm{~h} \mathrm{~kg}^{-1}$ and N/P ratio of 2.3 at the first cycle (Fig. $6 \mathrm{~d}$ ). Even after 10 cycles, the high $W_{\mathrm{G}}$ was maintained without a severe capacity decay (Supplementary Fig. 38). This outstanding Li-S pouch cell performance with the FeNC-EEB-1 cathode, compared with state-of-the-art pouch cell (Fig. 6 e and Supplementary Table 6), is attributed to the design of highly active Fe SACs by manipulating their local environments with $-\mathrm{SO}_{2} /$-S EEB sites.

In summary, we proposed that the introduction of $-\mathrm{SO}_{2} /$-S EEB sites adjacent to $\mathrm{Fe}-\mathrm{N}$-C catalysts improves the adsorption strength of sulfur species and promotes the Li-S electrochemistry kinetics of the catalysts, achieving a high-energy $\mathrm{Li}-\mathrm{S}$ pouch cell. The $-\mathrm{SO}_{2} /$-S EEB sites near the Fe-N-C catalysts function as additional binding sites for LiPS and exchange electrons with the Fe single atoms, modulating the Fe $d$ orbital level and LiPS $\mathrm{E}_{\text {ads }}$ of the Fe-N-C catalysts. Two different types of $\mathrm{S}$ species, $-\mathrm{SO}_{2}$ and $-\mathrm{S}$, show different LiPS adsorption characteristics and conversion behavior. In particular, the catalytic activity of Fe-N-C has a volcano relationship with the LiPS adsorption properties, and thus appropriate control of the $-\mathrm{SO}_{2} /-\mathrm{S}$ ratio of EEB sites allow sulfur species to adsorb moderately on the Fe single atoms, leading to favorable Li-S electrocatalysis of Fe-N-C. Consequently, high-energy Li-S pouch cell $\left(361.8 \mathrm{~W} \mathrm{~h} \mathrm{~kg}^{-1}\right)$ with low $\mathrm{E} / \mathrm{S}\left(2.0 \mu \mathrm{L} \mathrm{mg}^{-1}\right)$ and $\mathrm{E} / \mathrm{C}\left(1.9 \mu \mathrm{L}\left[\mathrm{mA} \mathrm{h}^{-1}\right)\right.$ ratios was successfully fabricated. This study is the first to demonstrate a strategy to manipulate the local environment of SACs by EEB sites, which will create a promising avenue for the design of advanced SAC-based cathodes for high-energy Li-S pouch cells.

\section{Method}

Materials. Poly (ethylene glycol)-block-poly (propylene glycol)-block-poly (ethylene glycol) (P123, $M_{n}$ : 5800), dibenzyl disulfide (DBDS, 98\%), sodium metabisulfite $\left(\mathrm{Na}_{2} \mathrm{~S}_{2} \mathrm{O}_{5}, 97 \%\right)$, furfuryl alcohol (98\%), tetraethyl orthosilicate (TEOS, 99\%), tetraethylene glycol dimethyl ether (TEGDME, 99\%), sodium silicate, 1,10-phenanthroline (99\%), and iron (III) chloride hexahydrate $\left(\mathrm{FeCl}_{3} \cdot 6 \mathrm{H}_{2} \mathrm{O}\right)$ were purchased from SigmaAldrich. Hydrochloric acid ( $\mathrm{HCl}, 35.0 \sim 37.0 \%)$ and glacial acetic acid $(99.8 \%)$ was obtained from SAMCHUN Pure Chemical Co. 1,3,5-Trimethylbenzene (mesitylene, $98 \%$ ) was purchased from Merck Millipore and hydrofluoric acid (HF, 48.0 51.0\%) was obtained from JT baker. Aluminum (III) chloride hexahydrate $\left(\mathrm{AlCl}_{3} \cdot 6 \mathrm{H}_{2} \mathrm{O}, 98 \%\right)$ was purchased from Kanto Chemical Co. All chemicals were used as received without further purification.

Synthesis of mesoporous carbon (MSU-F-C). MSU-F-C was prepared with hard template method and utilized as porous carbon framework in cathode of Li-S cell. First, MSU-F-SiO ${ }_{2}$ was prepared by sol-gel chemistry. P123 (9.6 mg) was dissolved in deionized (DI) water $(160 \mathrm{ml})$ and glacial acetic acid (4.58 $\mathrm{ml})$. Then, mesitylene $(9.26 \mathrm{ml})$ was added in the solution and stirred for $1 \mathrm{~h}$. A sodium silicate solution was also prepared by dissolving sodium silicate $(15.5 \mathrm{ml})$ into DI water $(240 \mathrm{ml})$. The sodium silicate solution was added in as-prepared P123 solution with stirring over 5 min, subsequently it was kept without stirring for $20 \mathrm{~h}$ at $40{ }^{\circ} \mathrm{C}$. The solution was aged in an oven at $100{ }^{\circ} \mathrm{C}$ oven for $24 \mathrm{~h}$. The aged solution was filtered and dissolved again in the mixture of DI water $(200 \mathrm{ml})$ and $\mathrm{HCl}$ solution $(5 \mathrm{ml})$. After $3 \mathrm{~h}$, the above solution was filtered again and as-obtained product was calcined at $550{ }^{\circ} \mathrm{C}$ for $4 \mathrm{~h}$. After collecting 
as-prepared MSU-F-SiO ${ }_{2}$, it was dispersed in ethanol and $\mathrm{AlCl}_{3} \cdot 6 \mathrm{H}_{2} \mathrm{O}(0.21 \mathrm{~g})$ was added to obtain a homogeneous mixture. After drying in the oven at $60^{\circ} \mathrm{C}$ to remove ethanol, the mixture was calcined at $550{ }^{\circ} \mathrm{C}$ for $4 \mathrm{~h}$ and $\mathrm{Al}-\mathrm{MSU}-\mathrm{F}-\mathrm{SiO}_{2}$ was obtained. The MSU-F-C was prepared by using Al-MSU-F-SiO ${ }_{2}$ as a hard template and furfuryl alcohol was used as a carbon precursor. After wet-impregnation of furfuryl alcohol to Al-MSU-F-SiO 2 , heat treatment was conducted at $850^{\circ} \mathrm{C}$ for $4 \mathrm{~h}$ in Ar atmosphere. After cooling at room temperature, Al-MSU-F-SiO 2 template was etched by $\mathrm{HF}$ solution to obtain MSU-F-C.

Synthesis of FeNC, FeNC-EEB-1, and FeNC-EEB-2. To prepare FeNC-EEB-1, DBDS (768 mg) was dissolved in ethanol $(100 \mathrm{ml})$. The appropriate amount of as-prepared DBDS solution was homogeneously impregnated into MSU-F-C with repetitive grinding until ethanol was completely evaporated. The DBDSimpregnated MSU-F-C was dried at $80^{\circ} \mathrm{C}$ for $1 \mathrm{~h}$, followed by heat treatment at $900{ }^{\circ} \mathrm{C}$ for $1 \mathrm{~h}$ in $\mathrm{Ar}$ atmosphere to generate low $-\mathrm{SO}_{2} / \mathrm{S}$ ratio EEB sites. For the formation of Fe-N-C catalysts into EEB sitesembedded MSU-F-C, Fe-N-C precursor solution was firstly prepared by dissolving $\mathrm{FeCl}_{3} \cdot 6 \mathrm{H}_{2} \mathrm{O}$ and 1, 10phenanthroline in ethanol. Then, this precursor solution was wet-impregnated into EEB sites embedded MSU-F-C with vigorous grinding. The mixture was dried at $80^{\circ} \mathrm{C}$ for $1 \mathrm{~h}$, followed by heat treatment at 900 ${ }^{\circ} \mathrm{C}$ for $1 \mathrm{~h}$ in $\mathrm{Ar}$ atmosphere. After cooling at room temperature, product was stirred in $1 \mathrm{M} \mathrm{HCl}$ solution to remove aggregated Fe metal residue, and FeNC-EEB-1 was obtained. The FeNC-EEB-2 was prepared by same method with FeNC-EEB-1, but using $\mathrm{Na}_{2} \mathrm{~S}_{2} \mathrm{O}_{5}$ to generate EEB sites instead of DBDS. The FeNC was also prepared by same method without the process for the generation of EEB sites.

Material characterization. A transmission electron microscopy (TEM; G2 F30 S-Twin, Tencai) and a scanning electron microscopy (SEM; S-4800 field emission, Hitachi) were used to observe the particle morphologies and porous structures of as-synthesized materials. The porous structure was further analyzed by nitrogen physisorption analysis at $77 \mathrm{~K}$ using a Micromeritics Tristar II 3020 system. X-ray diffraction (XRD) patterns were obtained using a RIGAKU D/MAX-2500V X-ray diffractometer (Cu Ka radiation, $\lambda=1.541 \AA ̊$ ). X-ray photoelectron spectroscopy (XPS) analysis was performed using VG Scientific Escalab 250 (Al $\mathrm{K}_{\mathrm{a}}$ ). High annular dark-field scanning TEM (STEM) and energy dispersive spectroscopy (EDS) were conducted for the detection of Fe single atom and further elemental distribution investigation by using a High-resolution TEM (HR-TEM; Titan cubed G2 60-300). X-ray absorption spectroscopy (XAS) analysis was performed at the 7D XAFS beamline at Pohang Accelerator Laboratory (PAL, Korea) to characterize the electronic structures of each Fe-N-C catalysts. Time-of-flight secondary ion mass spectrometry (ToF-SIMS) analyses were performed with $\mathrm{Cs}^{+}$sputter condition ( $\left.5 \mathrm{keV}, 35 \mathrm{nA}\right)$ and $\mathrm{Bi}^{+}$analysis condition ( $\left.30 \mathrm{keV}, 1 \mathrm{pA}\right)$.

Computational details. Density functional theory (DFT) calculations were performed using the Vienna ab initio Simulation Package (VASP). ${ }^{42,43}$ The Perdew-Burke-Ernzerhof (PBE) exchange-correlation functional and projector augmented-wave (PAW) pseudo-potential were adopted with spin polarization. ${ }^{44,45}$ FeNC models, force and energy criteria for structure optimization, k-point grid, plane wave cutoff and adsorption energy definitions are the same as in our previous study. ${ }^{34}$ The geometries of 
$S_{8}$ and $L_{2} S_{n}$ species $\left(n=8,6,4,2\right.$, and 1) refers the previous theoretical studies ${ }^{46,47}$ and they were reoptimized in $20 \times 20 \times 20 \AA^{3}$ box to calculate the gas-phase energy.

Fabrication of Li-S coin cell and characterization. A composites of sulfur (70 wt\%) with FeNC, FeNC-EEB1 , and FeNC-EEB-2 were prepared by heating the mixture at $155^{\circ} \mathrm{C}$ for $8 \mathrm{~h}$. To fabricate the working electrodes, a slurry was prepared by mixing the sulfur composite with each catalysts materials and polymeric binder (polyvinylidene difluoride, PVDF) in a weight ratio of 9:1 using a solvent ( $\mathrm{N}$-methyl-2pyrrolidone, NMP). The prepared slurry was coated on carbon coated Al foil, and dried at $60^{\circ} \mathrm{C}$ for $8 \mathrm{~h}$. Subsequently, the electrode was pressed and cut into a coin-shape. A porous polypropylene membrane (Celgard 2400, Welcos Ltd) was used as the separator. The electrochemical performance was measured using a coin-type cell (CR2032), and lithium metal with $200 \mu \mathrm{m}$ thickness was used as both the reference and counter electrodes. A solution containing $1.0 \mathrm{M}$ bis(trifluoromethane) sulfonamide lithium salt (LiTFSI) in a mixed solvent of dimethoxymethane and 1,3-dioxolane (DME/DOL, 1:1 volume ratio, PANAX E-TEC Co., Korea) with 2.0 wt.\% of lithium nitrate $\left(\mathrm{LiNO}_{3}, 99.99 \%\right.$ metal basis, Sigma-Aldrich) as an additive was used as an electrolyte. The average areal sulfur loading was controlled at $2.0 \mathrm{mg} \mathrm{cm}^{-2}$ and $\mathrm{E} / \mathrm{S}$ ratio was fixed to $10 \mu \mathrm{L} \mathrm{mg}^{-1}$ for the $\mathrm{Li}_{2} \mathrm{~S}$ nucleation/dissociation kinetic studies and coin-cell test at mild condition. For the coin cell test at harsh condition, electrodes with areal sulfur loading of $1.5-5.0 \mathrm{mg}$ $\mathrm{cm}^{-2}$ was fabricated and tested with E/S ratio of $4.0 \mu \mathrm{L} \mathrm{mg}^{-1}$. Galvanostatic charge-discharge analysis was performed in the potential range between 1.7 and $2.8 \mathrm{~V}\left(\mathrm{vs}\right.$. $\left.\mathrm{Li} / \mathrm{Li}^{+}\right)$at different current densities from 0.2 to $3.0 \mathrm{C}$ rate $\left(1 \mathrm{C}\right.$ rate $\left.\sim 1675 \mathrm{~mA} \mathrm{~g}^{-1}\right)$. The capacity was calculated based on the sulfur weight in the electrode. Cyclic voltammetry (CV) was conducted with scan rate of $0.2 \mathrm{mV} \mathrm{s}^{-1}$ in the potential range of 1.5-3.2 V (vs. $\left.\mathrm{Li} / \mathrm{Li}^{+}\right)$. For the in situ XRD analysis, 2032 type coin cell with $1.5 \mathrm{~mm}$ hole was designed and used for collecting the 2D mode XRD patterns. The sulfur loading and E/S ratio for in situ XRD analysis were fixed to $2.0 \mathrm{mg} \mathrm{cm}^{-2}$ and $10 \mu \mathrm{L} \mathrm{mg}^{-1}$. Each electrode was galvanostatically discharged and charged at $0.2 \mathrm{C}$ rate to clearly differentiate the $\mathrm{Li}_{2} \mathrm{~S}$ redox kinetics. All the in situ XRD data were collected at Korea Advanced Institute of Science and Technology Analysis Center for Research Advancement (KARA).

Fabrication of Li-S pouch cell and characterization. A composites of FeNC-EEB-1 (30 wt\%) and sulfur (70 wt\%) was prepared by same method (melt-diffusion) with Li-S coin-cell. To fabricate the working electrodes, a slurry was prepared by mixing the FeNC-EEB-1/sulfur composite and LA132 binder in a weight ratio of 9:1 using a solvent (DI water). The prepared slurry was coated on carbon coated Al foil $(20 \mu \mathrm{m})$, and dried at $60^{\circ} \mathrm{C}$ for $8 \mathrm{~h}$. Subsequently, the electrode was cut into $2.5 \mathrm{~cm}{ }^{\prime} 2.5 \mathrm{~cm}$ and $4 \mathrm{~cm}$ ' 4 $\mathrm{cm}$ shape. For the fabrication of Li-S pouch cell, Cu foil with $10 \mu \mathrm{m}$ was used as current collector for $\mathrm{Li}$ metal anode (thickness of $100 \mu \mathrm{m}$ ). The Celgard 2400 was used as a separator and pre-immersed in electrolyte for $6 \mathrm{~h}$ before the fabrication of Li-S pouch cell. Al and Ni tab was pasted to Cu and Al current collectors for applying and measuring current and potential. For the fabrication of $2.5 \mathrm{~cm}{ }^{\prime} 2.5 \mathrm{~cm} \mathrm{Li}-\mathrm{S}$ pouch cell, areal sulfur loading in cathode was fixed to $3.6 \mathrm{mg} \mathrm{cm}^{-2}$. The electrolyte amount was carefully calculated and used to achieve E/S ratio of $4.0 \mu \mathrm{L} \mathrm{mg}^{-1}$. For the fabrication of $4 \mathrm{~cm}^{\prime} 4 \mathrm{~cm} \mathrm{Li}$-S pouch cell, areal sulfur loading in cathode was fixed to $8.4 \mathrm{mg} \mathrm{cm}^{-2}$ and the electrolyte amount was controlled to 
achieve E/S ratio of 2.0 and $4.0 \mu \mathrm{L} \mathrm{mg}^{-1}$. The Li-S pouch cell was electrochemically tested at $30^{\circ} \mathrm{C}$ and specific capacity was calculated based on the amount of sulfur in cathode.

The total gravimetric energy density $\left(W_{\mathrm{G}}\right)$ of Li-S pouch cell was evaluated by below equations:

$$
W_{\mathrm{G}}=\frac{Q V}{\sum M_{j}}
$$

Where $Q$ and $V$ indicates the capacity $(\mathrm{mAh})$ and average operating voltage $(\mathrm{V})$, respectively and $M_{j}$ is the weight ( $\mathrm{g}$ ) of all component of the Li-S pouch cell. The $M_{j}$ includes the weight of Cu current collector, $\mathrm{Li}$ metal, separator, electrolyte, sulfur, binder, carbon/catalysts composite, and Al current collector.

\section{Declarations}

\section{Acknowledgement}

The authors acknowledge financial support from LG Energy Solution, Ltd. and the National Research Foundation of Korea (NRF) grant funded by the Korean government (NRF-2020R1A2C3004146 and 2021R1A2C3004019).

\section{Author contributions}

W.-G. Lim, C.-Y Park, H. Jung, J. W. Han and J. Lee conceived the research concept. W.-G. Lim, C.-Y Park and J. Lee designed the experiments and analyzed the results. H. Jung and J. W. Han performed DFT calculations and analysis. S. Kim, S. H. Kang, Y.-G. Lee, Y. C. Jeong, S. B. Yang and K. Sohn contributed to the scientific discussion and results analysis. W.-G. Lim, C.-Y Park, H. Jung, J. W. Han and J. Lee wrote the manuscript. J. W. Han and J. Lee supervised the project. All authors commented on the manuscript.

\section{Competing interests}

The authors declare that they have no competing interests.

\section{References}

1. Xue, W. et al. Intercalation-conversion hybrid cathodes enabling Li-S full-cell architectures with jointly superior gravimetric and volumetric energy densities. Nat. Energy 4, 374-382 (2019).

2. Liu, Y. T., Liu, S., Li, G. R. \& Gao, X. P. Strategy of enhancing the volumetric energy density for lithiumsulfur batteries. Adv. Mater. 33, 2003955 (2021).

3. Peng, H. J., Huang, J. Q., Cheng, X. B. \& Zhang, Q. Review on high-loading and high-energy lithiumsulfur batteries. Adv. Energy Mater. 7, 1700260 (2017). 
4. Lim, W. G. et al. Approaching ultrastable high-rate Li-S batteries through hierarchically porous titanium nitride synthesized by multiscale phase separation. Adv. Mater. 31, 1806547 (2019).

5. Pang, Q. et al. Tuning the electrolyte network structure to invoke quasi-solid state sulfur conversion and suppress lithium dendrite formation in Li-S batteries. Nat. Energy 3, 783-791 (2018).

6. Guo, W. et al. Artificial dual solid-electrolyte interfaces based on in situ organothiol transformation in lithium sulfur battery. Nat. Commun. 12, 1-13 (2021).

7. Cleaver, T., Kovacik, P., Marinescu, M., Zhang, T. \& Offer, G. Perspective-commercializing lithium sulfur batteries: are we doing the right research? J. Electrochem. Soc. 165, A6029 (2017).

8. Cheng, X.-B. et al. The gap between long lifespan Li-S coin and pouch cells: The importance of lithium metal anode protection. Energy Storage Mater. 6, 18-25 (2017).

9. Zhang, H., Ono, L. K., Tong, G., Liu, Y. \& Qi, Y. Long-life lithium-sulfur batteries with high areal capacity based on coaxial CNTs@TiN-TiO 2 sponge. Nat. Commun.12,1-8 (2021).

10. Cha, E. et al. 2D MoS 2 as an efficient protective layer for lithium metal anodes in high-performance Li-S batteries. Nat. Nanotech. 13, 337-344 (2018).

11. Zhao, M., Li, B.-Q., Zhang, X.-Q., Huang, J.-Q. \& Zhang, Q. A perspective toward practical lithiumsulfur batteries. ACS Cent. Sci. 6, 1095-1104 (2020).

12. Dörfler, S. et al. Challenges and key parameters of lithium-sulfur batteries on pouch cell level. Joule 4, 539-554 (2020).

13. Tan, G. et al. Burning lithium in $\mathrm{CS}_{2}$ for high-performing compact $\mathrm{Li}_{2} \mathrm{~S}$-graphene nanocapsules for Li-S batteries. Nat. Energy 2, 1-10 (2017).

14. Zhang, J., Li, Z., Chen, Y., Gao, S. \& Lou, X. W. Nickel-iron layered double hydroxide hollow polyhedrons as a superior sulfur host for lithium-sulfur batteries. Angew. Chem. 130, 11110-11114 (2018).

15. Bhargav, A., He, J., Gupta, A. \& Manthiram, A. Lithium-sulfur batteries: attaining the critical metrics. Joule 4, 285-291 (2020).

16. Zhao, M., Peng, Y.-Q., Li, B.-Q., Zhang, X.-Q. \& Huang, J.-Q. Regulation of carbon distribution to construct high-sulfur-content cathode in lithium-sulfur batteries. J. Energy Chem. 56, 203-208 (2021).

17. Cao, Y., Li, M., Lu, J., Liu, J. \& Amine, K. Bridging the academic and industrial metrics for nextgeneration practical batteries. Nat. Nanotech. 14, 200-207 (2019).

18. Zhang, M. et al. Adsorption-catalysis design in the lithium-sulfur battery. Adv. Energy Mater. 10, 1903008 (2020).

19. Wang, P. et al. Emerging Catalysts to Promote Kinetics of Lithium-Sulfur Batteries. Adv. Energy Mater. 11, 2002893 (2021).

20. Lim, W. G., Kim, S., Jo, C. \& Lee, J. A comprehensive review of materials with catalytic effects in Li-S batteries: enhanced redox kinetics. Angew. Chem. Int. Ed. 131, 18920-18931 (2019). 
21. Peng, L. et al. A fundamental look at electrocatalytic sulfur reduction reaction. Nat. Catal. 3, 762-770 (2020).

22. Luo, D. et al. Design of Quasi-MOF Nanospheres as a Dynamic Electrocatalyst toward Accelerated Sulfur Reduction Reaction for High-Performance Lithium-Sulfur Batteries. Adv. Mater. 2105541 (2021).

23. Lu, C., Fang, R. \& Chen, X. Single-Atom Catalytic Materials for Advanced Battery Systems. Adv. Mater. 32, 1906548 (2020).

24. Du, Z. et al. Cobalt in nitrogen-doped graphene as single-atom catalyst for high-sulfur content lithium-sulfur batteries. J. Am. Chem. Soc. 141, 3977-3985 (2019).

25. Zhao, C. et al. A high-energy and long-cycling lithium-sulfur pouch cell via a macroporous catalytic cathode with double-end binding sites. Nat. Nanotech. 16, 166-173 (2021).

26. Han, Z. et al. Engineering d-p Orbital Hybridization in Single-Atom Metal-Embedded ThreeDimensional Electrodes for Li-S Batteries. Adv. Mater., 2105947 (2021).

27. Wang, J. et al. Single Atom-Based Nanoarchitectured Electrodes for High-Performance LithiumSulfur Batteries. Adv. Mater. Interfaces 8, 2002159 (2021).

28. Wang, F. et al. Single-Atom Electrocatalysts for Lithium Sulfur Batteries: Progress, Opportunities, and Challenges. ACS Mater. Lett. 2, 1450-1463 (2020).

29. Zhang, Y. et al. Engineering Oversaturated Fe- $\mathrm{N}_{5}$ Multifunctional Catalytic Sites for Durable LithiumSulfur Batteries. Angew. Chem. Int. Ed. (2021).

30. Ma, C. et al. Engineering Fe-N Coordination Structures for Fast Redox Conversion in Lithium-Sulfur Batteries. Adv. Mater., 2100171 (2021).

31. Tao, Y. et al. Kinetically-enhanced polysulfide redox reactions by $\mathrm{Nb}_{2} \mathrm{O}_{5}$ nanocrystals for high-rate lithium-sulfur battery. Energy Environ. Sci. 9, 3230-3239 (2016).

32. Li, Y.-J., Fan, J.-M., Zheng, M.-S. \& Dong, Q.-F. A novel synergistic composite with multi-functional effects for high-performance Li-S batteries. Energy Environ. Sci. 9, 1998-2004 (2016).

33. Tao, X. et al. Balancing surface adsorption and diffusion of lithium-polysulfides on nonconductive oxides for lithium-sulfur battery design. Nat. Commun. 7, 1-9 (2016).

34. Mun, Y. et al. Versatile strategy for tuning ORR activity of a single $\mathrm{Fe}-\mathrm{N}_{4}$ site by controlling electronwithdrawing/donating properties of a carbon plane. J. Am. Chem. Soc. 141, 6254-6262 (2019).

35. Hasegawa, G. et al. High-level doping of nitrogen, phosphorus, and sulfur into activated carbon monoliths and their electrochemical capacitances. Chem. Mater. 27, 4703-4712 (2015).

36. Jung, E. et al. Atomic-level tuning of Co-N-C catalyst for high-performance electrochemical $\mathrm{H}_{2} \mathrm{O}_{2}$ production. Nat. Mater. 19, 436-442 (2020).

37. Lim, W.-G. et al. Synergistic effect of molecular-type electrocatalysts with ultrahigh pore volume carbon microspheres for lithium-sulfur batteries. ACS Nano 12, 6013-6022 (2018).

38. Fan, F. Y., Carter, W. C. \& Chiang, Y. M. Mechanism and kinetics of $\mathrm{Li}_{2} \mathrm{~S}$ precipitation in lithium-sulfur batteries. Adv. Mater. 27, 5203-5209 (2015). 
39. Shen, Z. et al. Rational Design of a $\mathrm{Ni}_{3} \mathrm{~N}_{0.85}$ Electrocatalyst to Accelerate Polysulfide Conversion in Lithium-Sulfur Batteries. ACS Nano 14, 6673-6682 (2020).

40. Li, R. et al. Amorphization-induced surface electronic states modulation of cobaltous oxide nanosheets for lithium-sulfur batteries. Nat. Commun. 12, 1-8 (2021).

41. Shang, C. et al. Dissolving Vanadium into Titanium Nitride Lattice Framework for Rational Polysulfide Regulation in Li-S Batteries. Adv. Energy Mater. 11, 2003020 (2021).

42. Kresse, G. \& Hafner, J. Ab initio molecular dynamics for liquid metals. Phys. Rev. B 47, 558 (1993).

43. Kresse, G. \& Furthmüller, J. Efficient iterative schemes for ab initio total-energy calculations using a plane-wave basis set. Phys. Rev. B 54, 11169 (1996).

44. Blöchl, P. E. Projector augmented-wave method. Phys. Rev. B 50, 17953 (1994).

45. Perdew, J. P., Burke, K. \& Ernzerhof, M. Generalized gradient approximation made simple. Phys. Rev. Lett. 77, 3865 (1996).

46. Yi, G. S., Sim, E. S. \& Chung, Y.-C. Effect of lithium-trapping on nitrogen-doped graphene as an anchoring material for lithium-sulfur batteries: a density functional theory study. Phys. Chem. Chem. Phys. 19, 28189-28194 (2017).

47. Zhang, T., Chen, Z., Zhao, J. \& Ding, Y. Metal- $\mathrm{N}_{4} /$ graphene as an efficient anchoring material for lithium-sulfur batteries: A computational study. Diam. Relat. Mater. 90, 72-78 (2018).

\section{Figures}




\section{Design of advanced single atom catalysts}

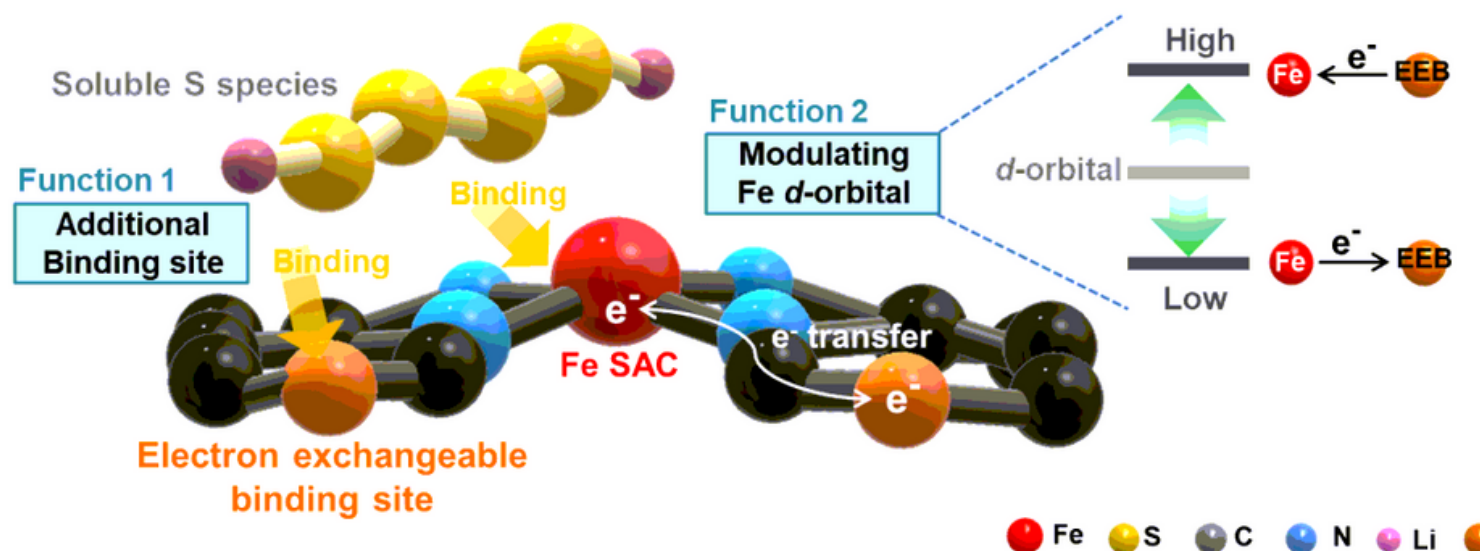

(b)

\section{- S confinement}

- Contact with Fe SACs

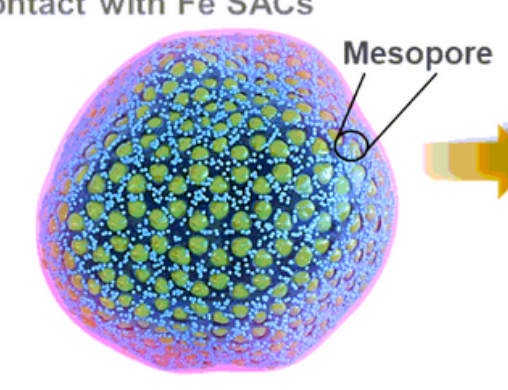

High S loading cathode

High energy Li-S pouch cell

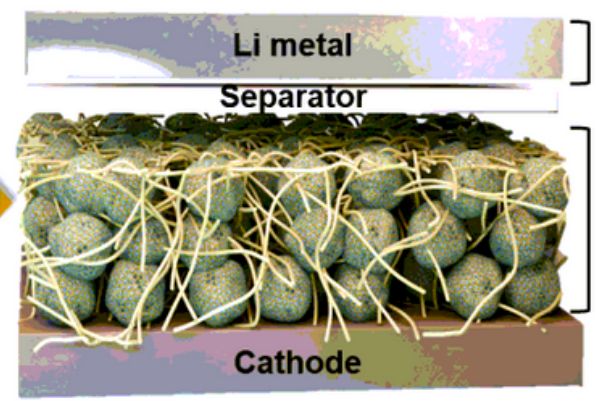

$\sim 100 \%$
excess

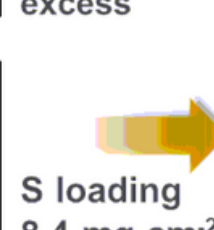

Energy density $361.8 \mathrm{~W} \mathrm{~h} \mathrm{~kg}^{-1}$

$8.4 \mathrm{mg} \mathrm{cm}^{-2}$

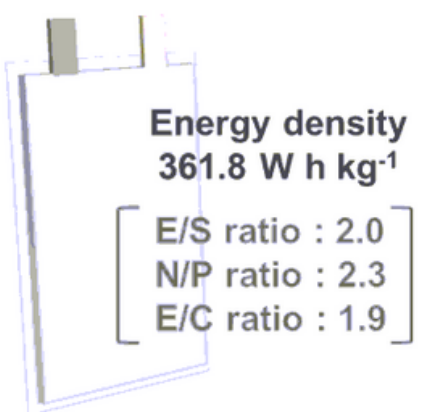

Figure 1

(a) Schematic description of electron exchangeable binding (EEB) sites near Fe-N-C catalysts. The Li-S electrochemistry on Fe SACs is enhanced by controlling the LiPS adsorption properties; EEB sites provide additional binding sites by the forming bonds with LiPS species (function 1) and also modulate Fe $d$ orbital level by the electron exchange with Fe-N-C catalysts (function 2). (b) Schematic presentation of the fabrication process for a high-energy Li-S pouch cell satisfying low E/S, N/P, and E/C ratios. 
(a)

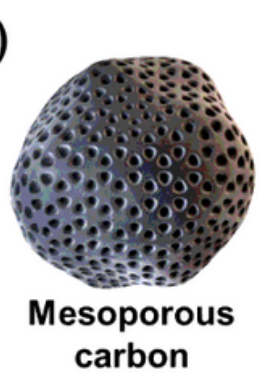

(b)

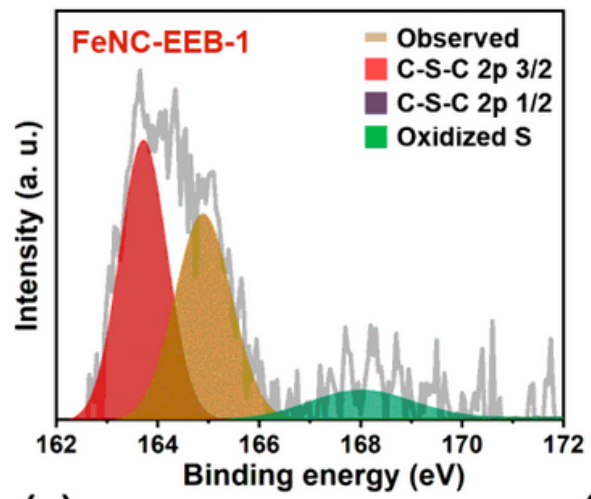

(e)

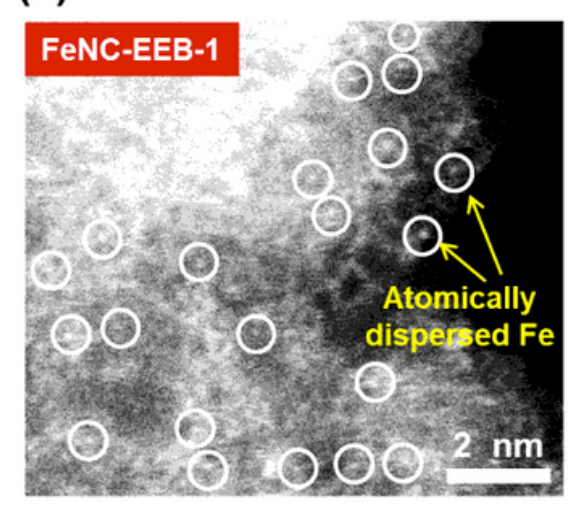

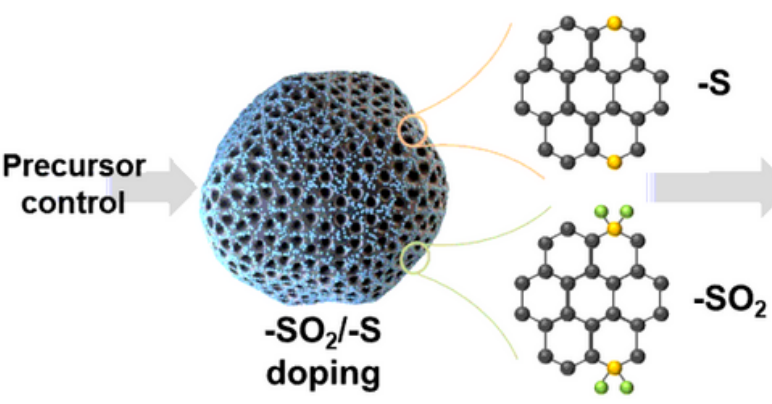

(c)

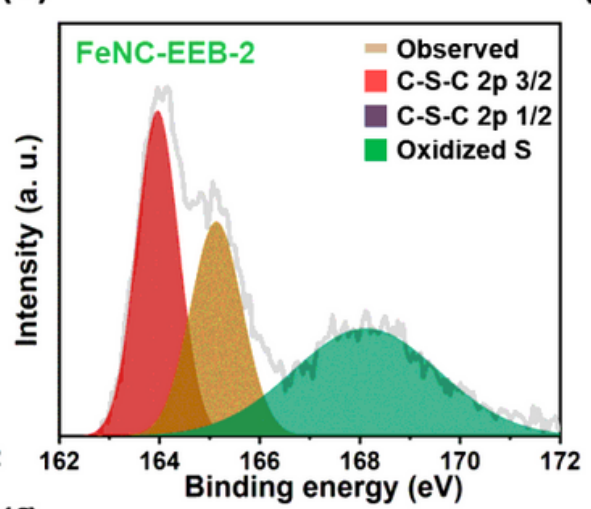

(f)

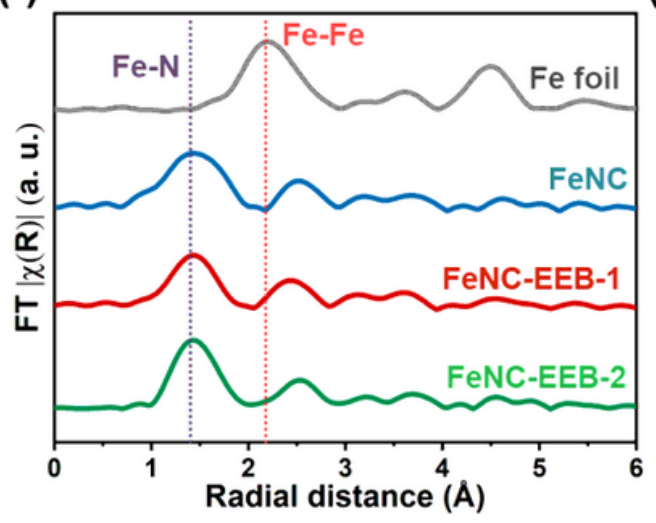

(d)

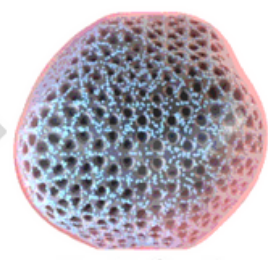

Fe-N-C site generation

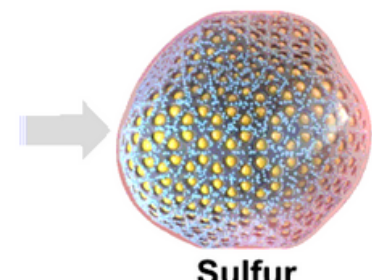

impregnation

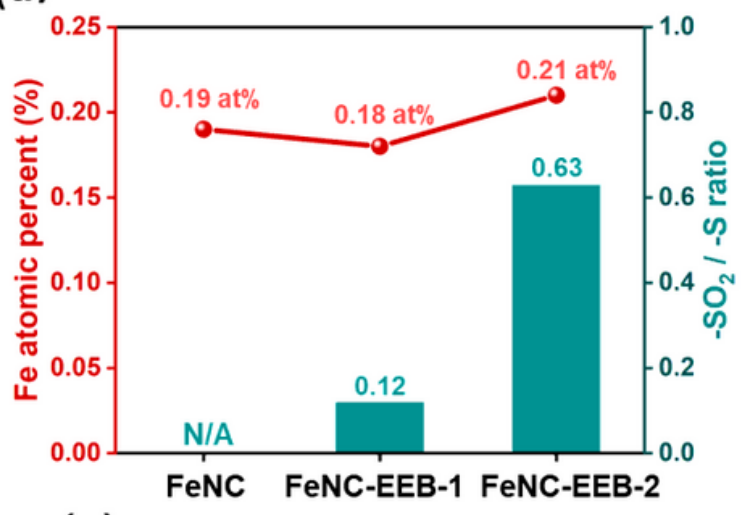

(g)

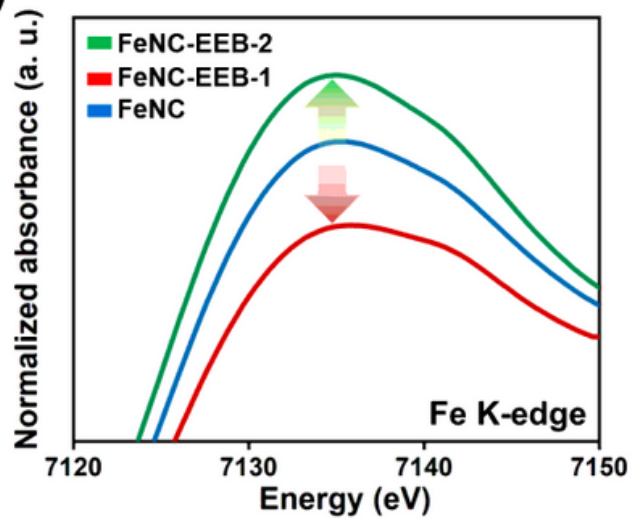

Figure 2

(a) Schematic description of the synthetic process to prepare - $\mathrm{SO}_{2} /-\mathrm{S}$ EEB sites-assisted Fe-N-C catalysts.

(b) XPS S 2p spectrum of FeNC-EEB-1 and (c) FeNC-EEB-2. (d) Fe contents measured by inductively coupled plasma atomic emission spectroscopy (ICP-AES) and $-\mathrm{SO}_{2} /$-S ratios of FeNC, FeNC-EEB-1, and FeNC-EEB-2. (e) STEM image of FeNC-EEB-1. Fe single atoms are highlighted by white circles. (f) FTEXAFS spectra of the reference Fe foil, FeNC, FeNC-EEB-1, and FeNC-EEB-2. (g) Magnified white line of Fe K-edge XANES in FeNC, FeNC-EEB-1, and FeNC-EEB-2. Shift of the white line intensity is attributed to the electron density change of Fe single atoms (i.e., shift of Fe $d$-band center) by electron exchange with neighboring $-\mathrm{SO}_{2} /-\mathrm{S}$ EEB sites. 
(a)
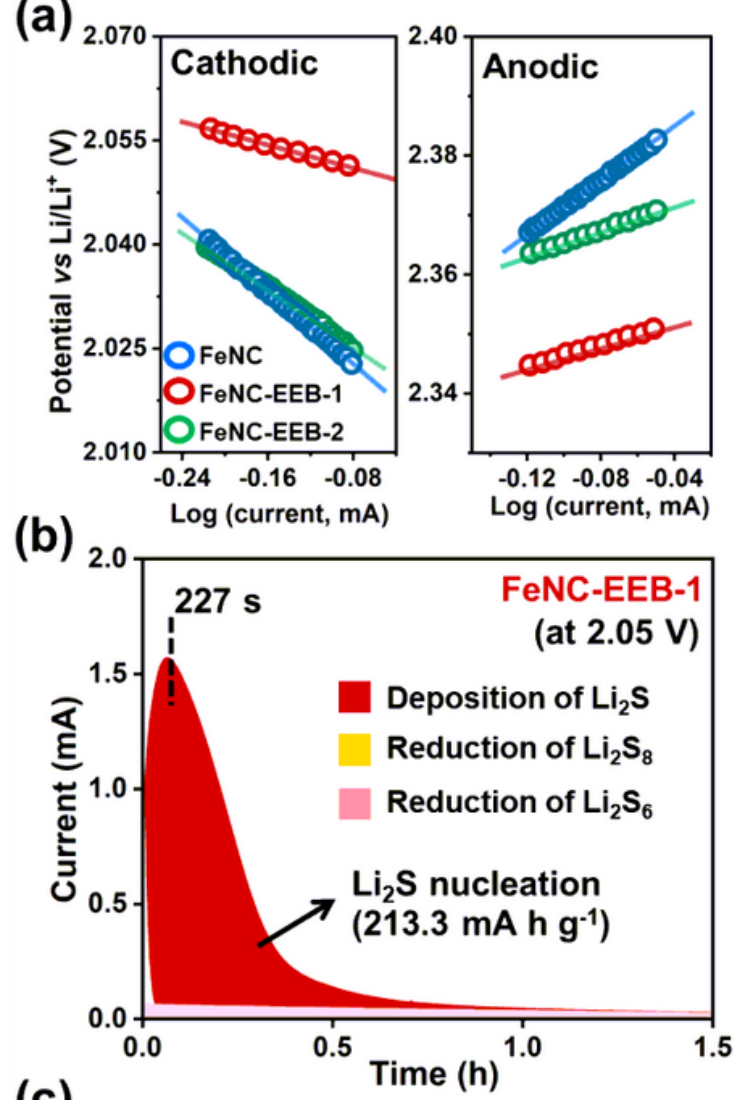

(c)

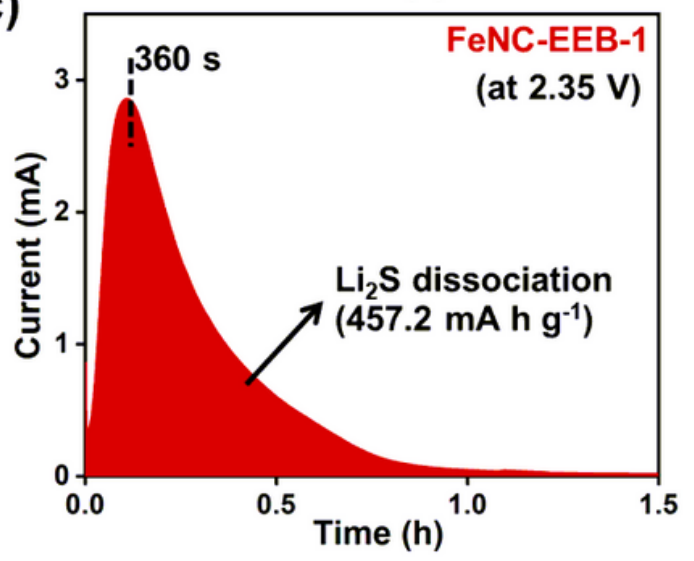

(d)

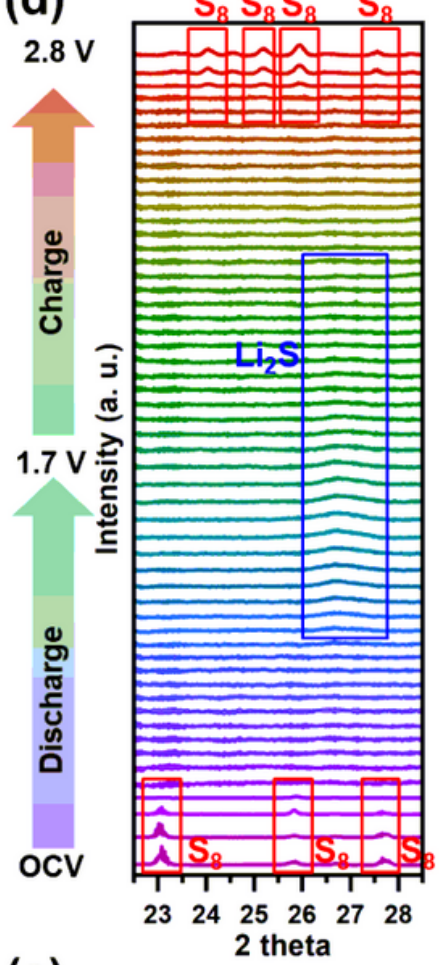

(e)

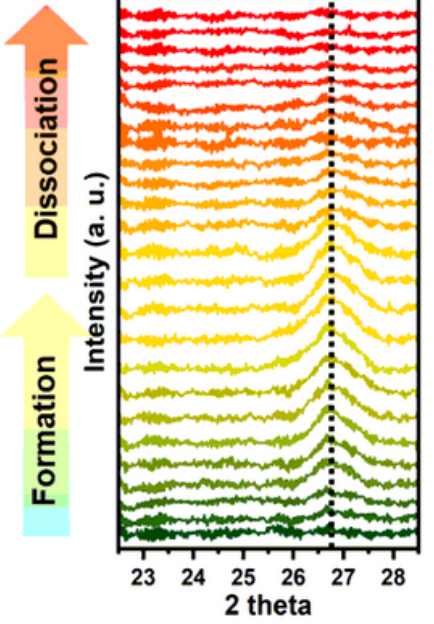

(f)
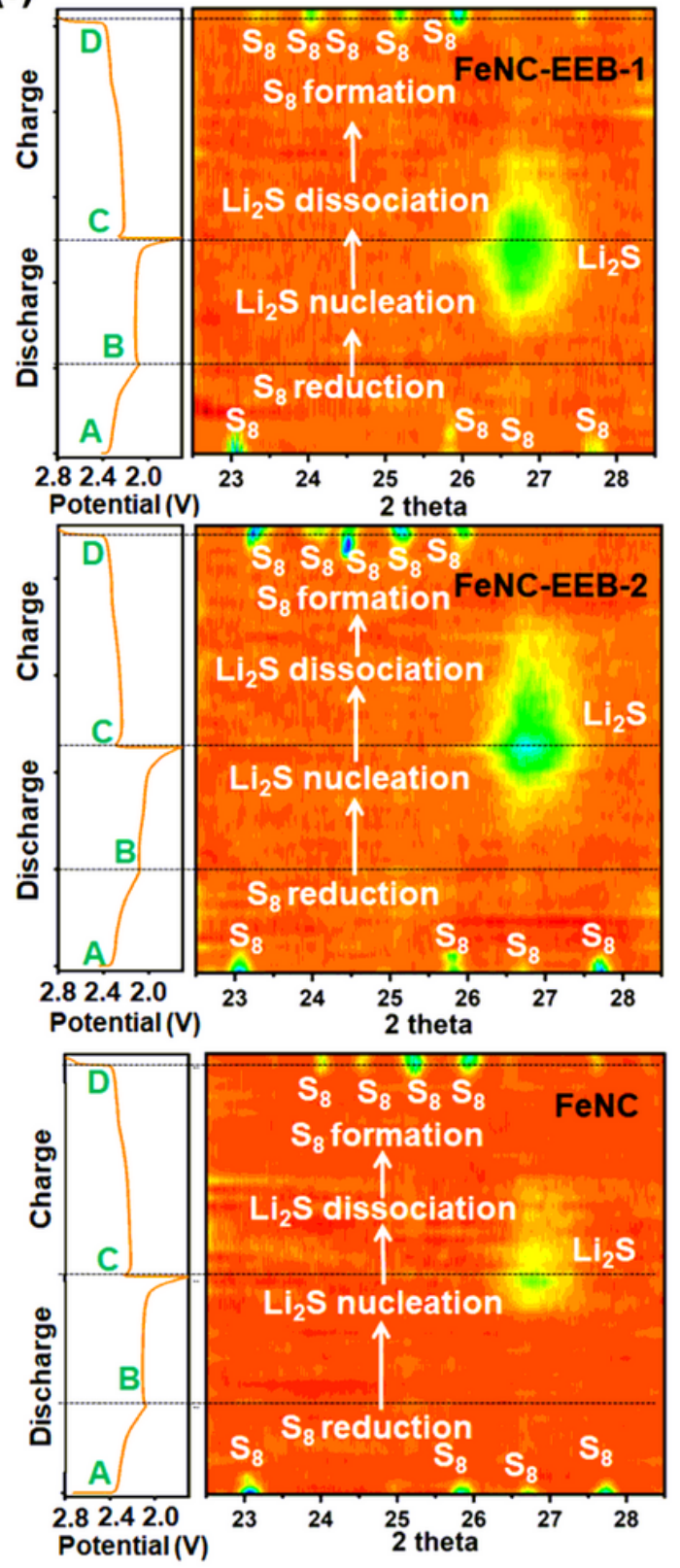

Figure 3

(a) Tafel plots for cathodic and anodic reactions of FeNC, FeNC-EEB-1, and FeNC-EEB-2. (b) Potentiostatic discharge curves of FeNC-EEB-1 at $2.05 \mathrm{~V}$. (c) Potentiostatic charge curves of FeNC-EEB-1 at $2.35 \mathrm{~V}$. (d) In situ XRD patterns of FeNC-EEB-1 for the first discharge/charge process at a $0.2 \mathrm{C}$ rate. Crystalline peaks of $\mathrm{S}_{8}$ and $\mathrm{Li}_{2} \mathrm{~S}$ correspond to orthorhombic (JCPDS No. 00-008-0247) and cubic (JCPDS No. 00-0230369) phases, respectively. (e) Magnified in situ XRD patterns of FeNC-EEB-1 in the region of $\mathrm{Li}_{2} \mathrm{~S}$ nucleation and dissociation. (f) Contour in situ XRD images and corresponding voltage profiles of FeNCEEB-1, FeNC-EEB-2, and FeNC electrodes. For these $\mathrm{Li}_{2} \mathrm{~S}$ nucleation/dissociation kinetic studies, the areal sulfur loading in the cathode and the $\mathrm{E} / \mathrm{S}$ ratio was fixed to $2.0 \mathrm{mg} \mathrm{cm}^{-2}$ and $10 \mu \mathrm{L} \mathrm{mg}^{-1}$, respectively. 
(a) $\quad \mathrm{FeNC}=\mathrm{FeNC}-\mathrm{S} \quad \mathrm{FeNC}_{-} \mathrm{SO}_{2}$

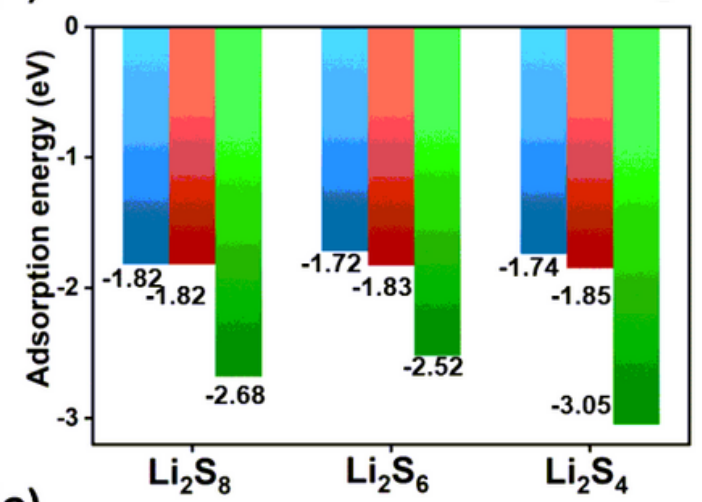

(c) $\quad \mathrm{FeNC} \quad \mathrm{FeNC}-\mathrm{S} \quad \mathrm{FeNC}-\mathrm{SO}_{2}$

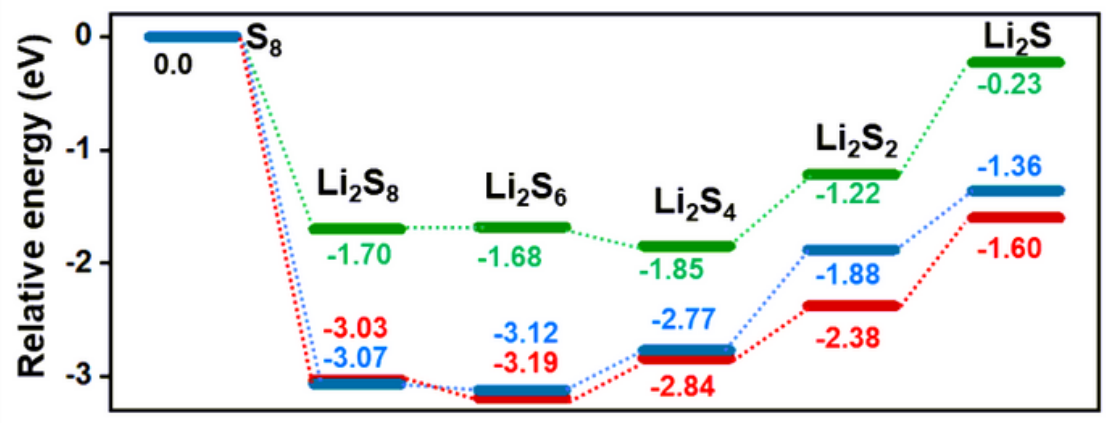

Reaction coordinate

(e) Weak adsorption

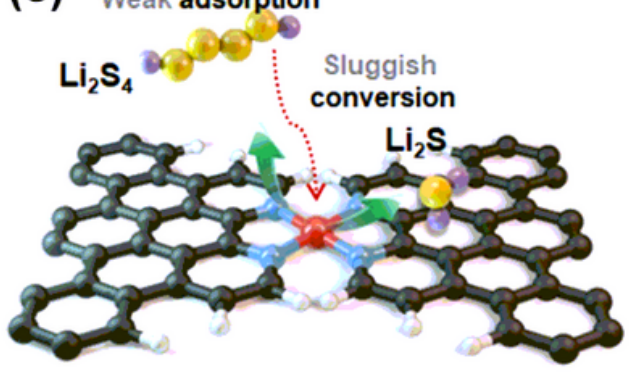

Fe-N-C site

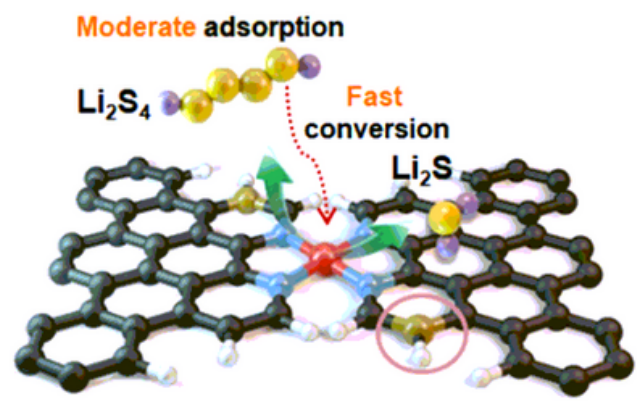

-S doped Fe-N-C site

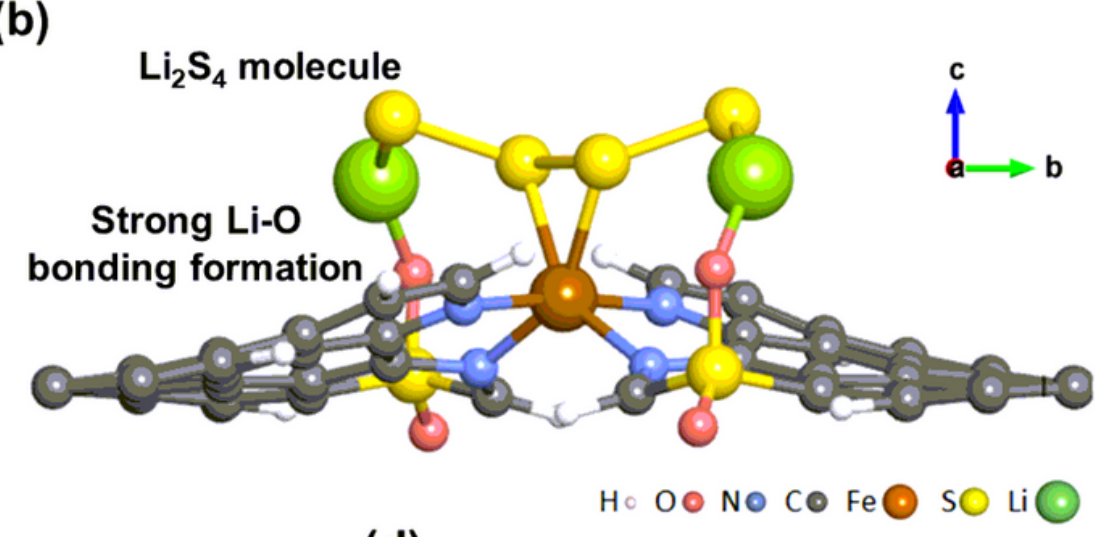

(d)

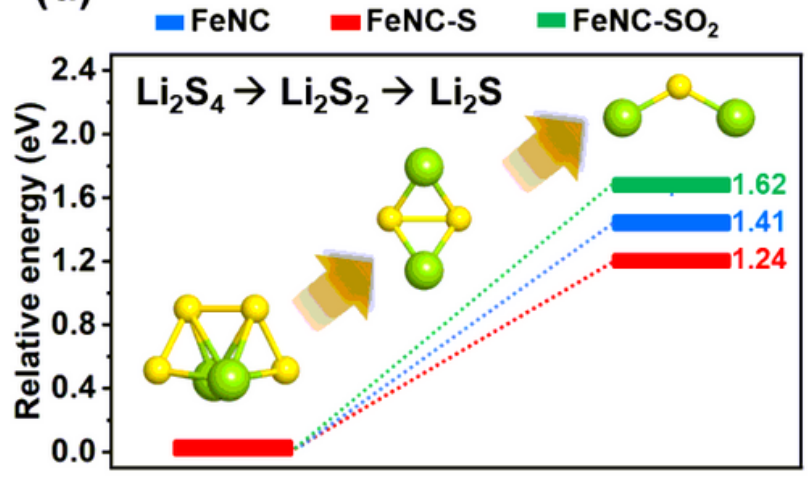

Reaction coordinate

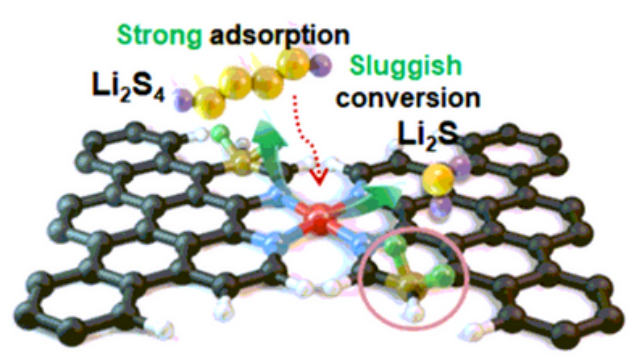

$-\mathrm{SO}_{2}$ doped $\mathrm{Fe}-\mathrm{N}-\mathrm{C}$ site

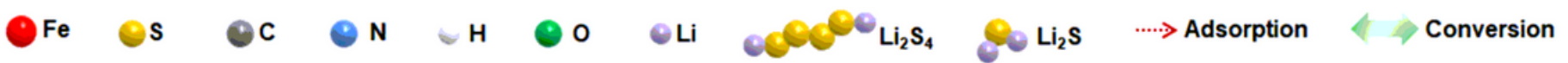

Figure 4

(a) Calculated adsorption energies of LiPS species on FeNC, FeNC-S, and FeNC-SO 2 . (b) Molecular configuration of $\mathrm{Li}_{2} \mathrm{~S}_{4}$ adsorption on FeNC-SO $\mathrm{S}_{2}$. (c) Relative energy diagrams for the sulfur conversion reaction. (d) Calculated $\Delta E$ values for the conversion steps of $\mathrm{Li}_{2} \mathrm{~S}_{4}$ to $\mathrm{Li}_{2} \mathrm{~S}$ in FeNC, FeNC-S, and FeNC$\mathrm{SO}_{2}$. (e) Schematics of LiPS adsorption and conversion behaviors on Fe-N-C catalysts with different local environments. 
(a)

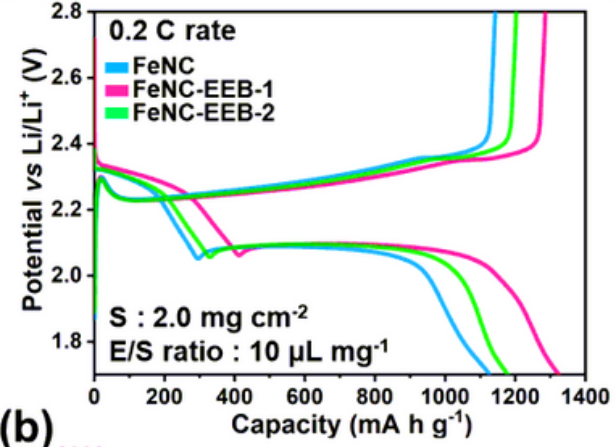

(b)

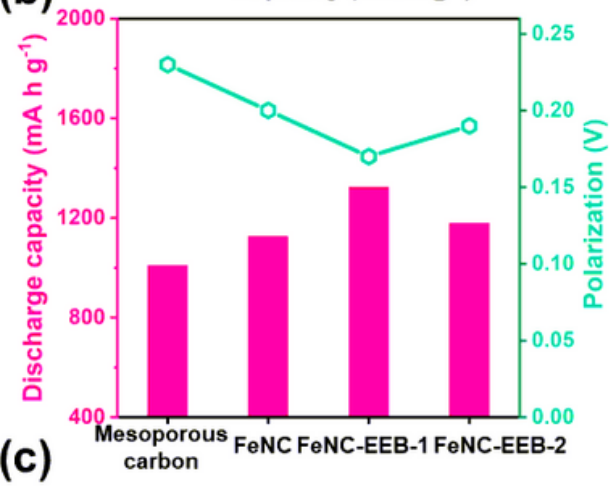

(c)

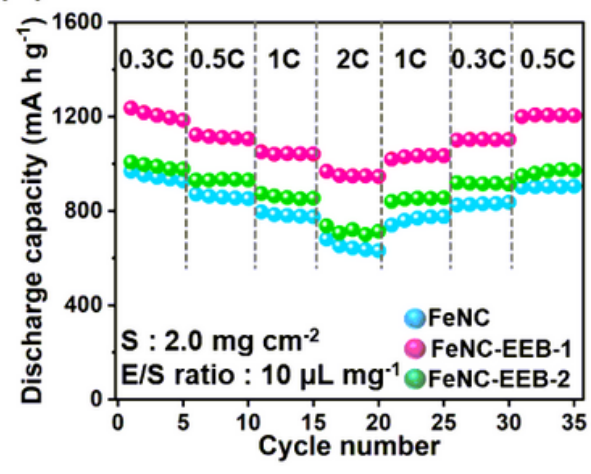

(d)
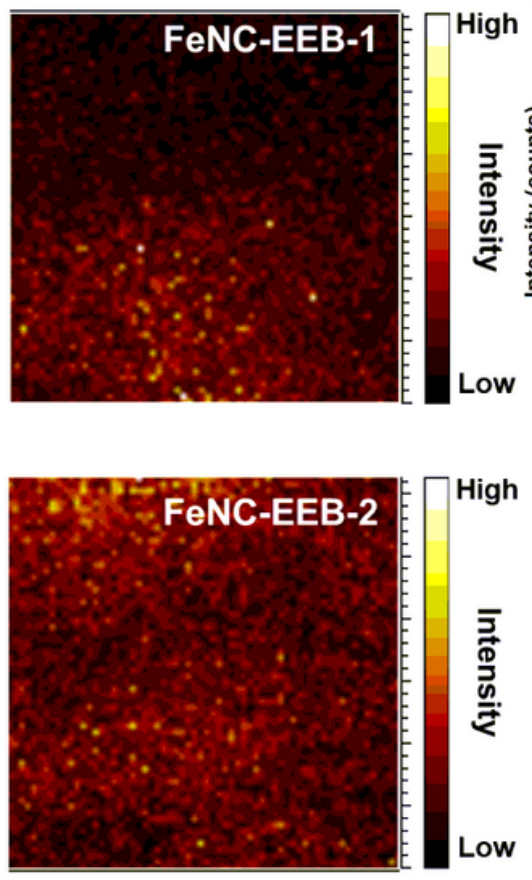

(e)

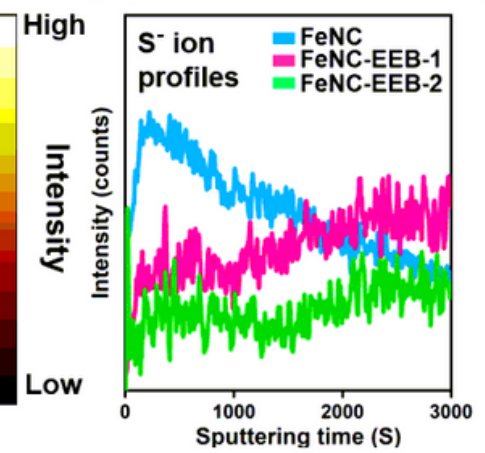

(f)

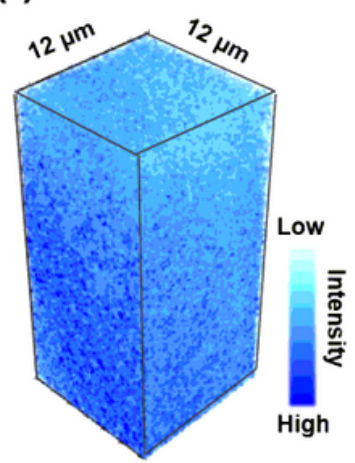

(g)

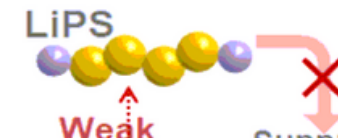

Weạk suppressed dissolụition Shuttle effect

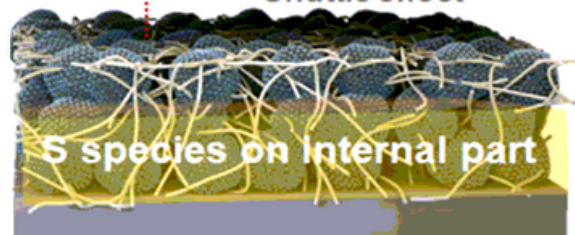

(h)
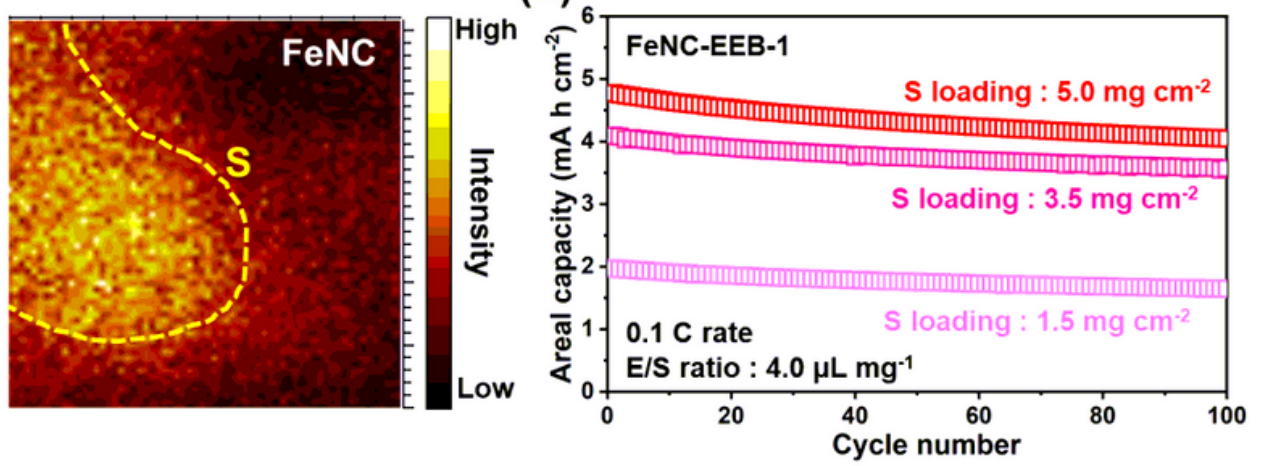

Figure 5

(a) Initial voltage profiles of FeNC, FeNC-EEB-1, and FeNC-EEB-2 at the $0.2 \mathrm{C}$ rate. (b) Summary of the discharge capacities and polarization potentials at the $0.2 \mathrm{C}$ rate. (c) Rate capabilities of FeNC, FeNCEEB-1, and FeNC-EEB-2 with different current densities from the 0.3 to $2.0 \mathrm{C}$ rate. For all the coin-cell studies in (a-c), the electrode with a sulfur areal loading of $2.0 \mathrm{mg} \mathrm{cm}^{-2}$ and $\mathrm{E} / \mathrm{S}$ ratio of $10 \mu \mathrm{L} \mathrm{mg} \mathrm{m}^{-1}$ was utilized. (d) ToF-SIMS $\mathrm{S}^{-}$ion mappings on the top surface and (e) ToF-SIMS depth profiles of each electrode after operating 20 cycles at a $0.2 \mathrm{C}$ rate. (f) ToF-SIMS 3D rendering $\mathrm{S}^{-}$depth profile image of the cycled FeNC-EEB-1 electrode. (g) Schematics of the LiPS dissolution behavior in EEB sites-embedded S cathode. (h) Cycle performance of FeNC-EEB-1 at a $0.1 \mathrm{C}$ rate with different sulfur areal loadings. FeNCEEB-1 exhibited $1300 \mathrm{~mA} \mathrm{~h} \mathrm{~g}^{-1}\left(1.95 \mathrm{~mA} \mathrm{~h} \mathrm{~cm}^{-2}\right)$ with a $\mathrm{S}$ loading of $1.5 \mathrm{mg} \mathrm{cm}^{-2}$ and $1166 \mathrm{~mA} \mathrm{~h} \mathrm{~g}^{-1}(4.08$ $\mathrm{mA} \mathrm{h} \mathrm{cm}{ }^{-2}$ ) with a $\mathrm{S}$ loading of $3.5 \mathrm{mg} \mathrm{cm}^{-2}$. Pre-cycling for 5 cycles at a $0.02 \mathrm{C}$ rate was performed before the cycling at a $0.1 \mathrm{C}$ rate and the $\mathrm{E} / \mathrm{S}$ ratio was fixed to $4.0 \mu \mathrm{L} \mathrm{mg}^{-1}$. 
(a)

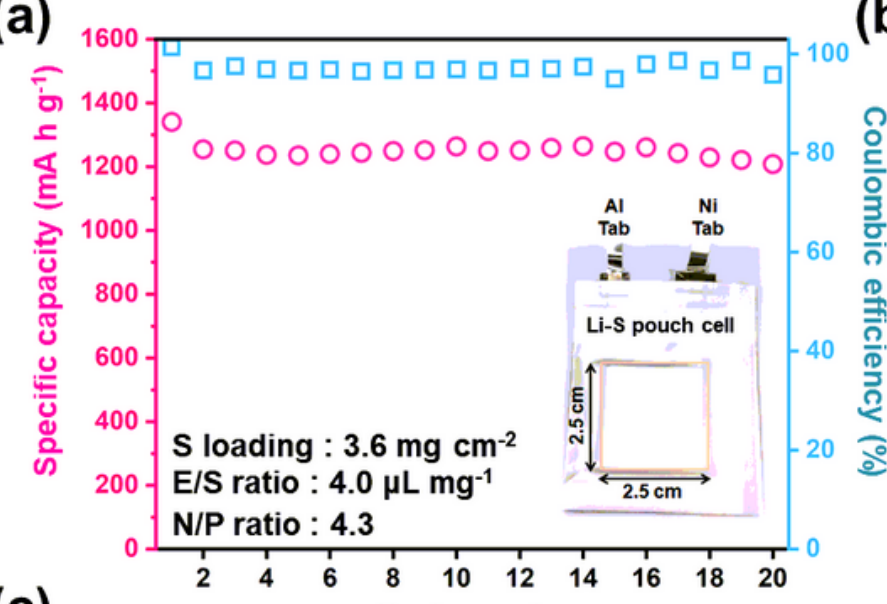

(c)
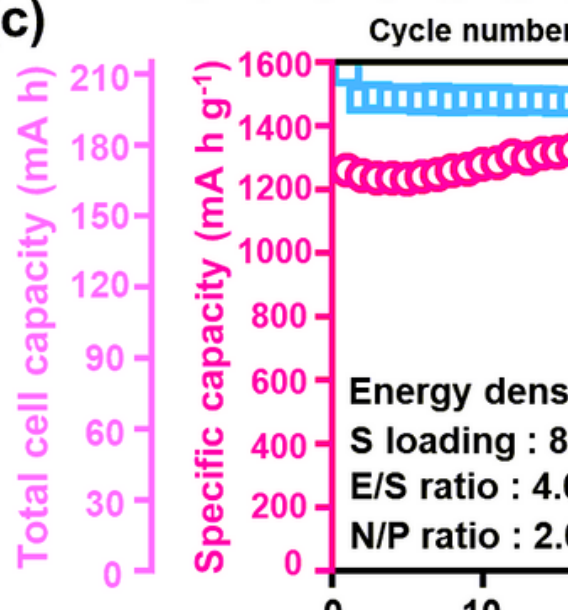

(b)

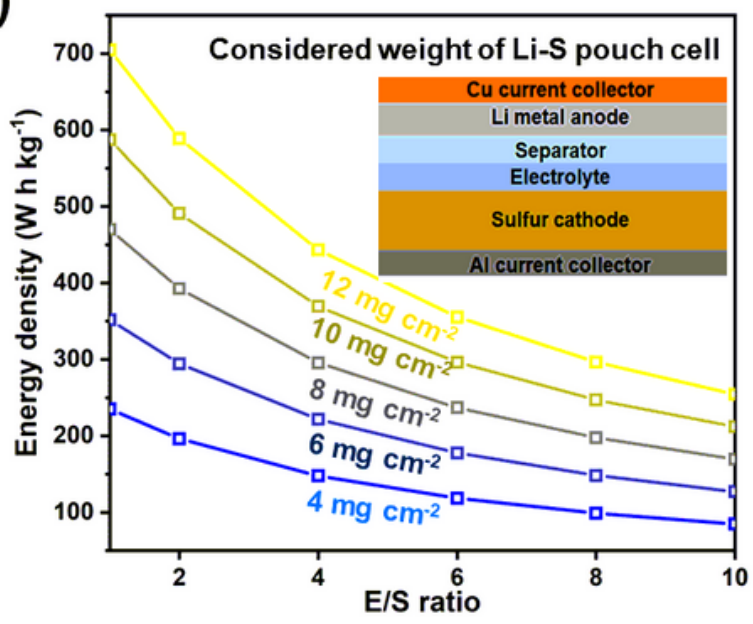

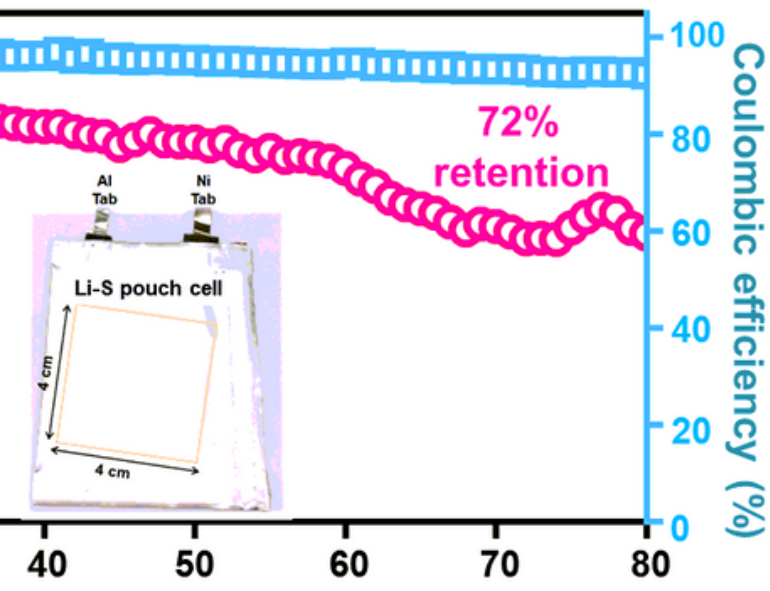

Cycle number


Figure 6

(a) Galvanostatic test results of a $2.5 \mathrm{~cm}^{\prime} 2.5 \mathrm{~cm} \mathrm{Li}-\mathrm{S}$ pouch cell at $0.18 \mathrm{~mA} \mathrm{~cm}^{-2}$. (b) Calculated correlation plot of $W_{\mathrm{G}}$ with the $\mathrm{E} / \mathrm{S}$ ratio and sulfur areal loading. For the calculation, the capacity and average potential were fixed to $1200 \mathrm{~mA} \mathrm{~h} \mathrm{~g}^{-1}$ and $2.1 \mathrm{~V}$, respectively. (c) Galvanostatic test results of the $4 \mathrm{~cm}^{\prime} 4 \mathrm{~cm}$ Li-S pouch cell with an E/S ratio of $4.0 \mu \mathrm{L} \mathrm{mg}^{-1}$ at $0.42 \mathrm{~mA} \mathrm{~cm}^{-2}$. (d) Initial voltage profiles of 
the $4 \mathrm{~cm}^{\prime} 4 \mathrm{~cm}$ Li-S pouch cell with an E/S ratio of $2.0 \mu \mathrm{L} \mathrm{mg}^{-1}$ at $0.42 \mathrm{~mA} \mathrm{~cm}^{-2}$. (e) Comparison of the Li$S$ pouch cell performance with recently reported studies.

\section{Supplementary Files}

This is a list of supplementary files associated with this preprint. Click to download.

- Supplementarylnformation.docx 